\title{
Status of Solar Sail Propulsion: Moving Toward an Interstellar Probe
}

\author{
Les Johnson, Roy M. Young, and Edward E. Montgomery IV
}

NASA George C. Marshall Space Flight Center, Huntsville, AL 35812

\begin{abstract}
NASA's In-Space Propulsion Technology Program has developed the firstgeneration of solar sail propulsion systems sufficient to accomplish inner solar system science and exploration missions. These first-generation solar sails, when operational, will range in size from 40 meters to well over 100 meters in diameter and have an areal density of less than 13 grams-per-square meter. A rigorous, multiyear technology development effort culminated last year in the testing of two different 20-meter solar sail systems under thermal vacuum conditions. This effort provided a number of significant insights into the optimal design and expected performance of solar sails as well as an understanding of the methods and costs of building and using them. In a separate effort, solar sail orbital analysis tools for mission design were developed and tested. Laboratory simulations of the effects of long-term space radiation exposure were also conducted on two candidate solar sail materials. Detailed radiation and charging environments were defined for mission trajectories outside the protection of the earth's magnetosphere, in the solar wind environment. These were used in other analytical tools to prove the adequacy of sail design features for accommodating the harsh space environment.

Preceding, and in conjunction with these technology efforts, NASA sponsored several mission application studies for solar sails, including one that would use an evolved sail capability to support humanity's first mission into nearby interstellar space. The proposed mission is called the Interstellar Probe. The Interstellar Probe might be accomplished in several ways. A 200-meter sail, with an areal density approaching 1 gram-per-square meter, could accelerate a robotic probe to the very edge of the solar system in just under 20 years from launch. A sail using the technology just demonstrated could make the same mission, but take significantly longer. Conventional chemical propulsion systems would require even longer flight times. Spinner sails of the type being explored by the Japanese may also be a good option, but the level of maturity in that technology is not clear. While the technology to support a 200-meter, ultralightweight sail mission is not yet in hand, the recent NASA investments in solar sail technology are an essential first step toward making it a reality.

This paper will describe the status of solar sail propulsion within NASA, near-term solar sail mission applications, and the plan to advance the technology to the point where the Interstellar Probe mission can be flown.
\end{abstract}

Keywords: Solar Sail Propulsion, Interstellar Probe, Interstellar Travel PACS: Spaceborne and space-research instruments, 07.87.+v, 95.55.-n 


\section{INTRODUCTION}

The In-Space Propulsion Technology (ISPT) Program is in its fifth year and significant strides have been made in the advancement of key transportation technologies that will enable or enhance future robotic science and deep space exploration missions. At the program's inception, a set of technology investment priorities were established using a NASA-wide prioritization process and, for the most part, these priorities have changed little-thus allowing a consistent framework in which to fund and manage technology development. Technologies in the portfolio include aerocapture, advanced chemical propulsion, solar electric propulsion, and solar sail propulsion.

Solar sails are large, lightweight structures that achieve thrust by reflecting solar photons. Two different 20-meter solar sail systems were developed and successfully completed deployment and functional vacuum testing during 2005 in NASA Glenn's Space Power Facility at Plum Brook Station, Sandusky, Ohio. The sails were designed and developed by ATK Space Systems and L'Garde, respectively. The sail systems consist of a central structure with four deployable booms that support the sails. These sail designs are robust enough for deployments in a one atmosphere, one gravity environment and are scalable to much larger solar sails-perhaps as much as 150 meters on each side.

First-generation sails will vary in size from 100-200 meters, depending on mission destination, and typically would be three-axis stabilized. They would be compacted and stowed for launch. Once deployed, the sails would be supported by ultralightweight trusses. Solar sails are composed of flat, smooth material covered with a reflective coating and supported by the ultralightweight structures, which are attached to a central hub. Near-term sails likely will use aluminized Mylar or CP-1. Both are materials previously flown in space and are currently under test for long-term exposure to relevant environments for potential solar sail missions. More robust sails might use a meshwork of interlocking carbon fibers.

Solar sail propulsion (SSP) is one of ISPT's three high-priority investment areas, with the objective of near-term verification and development of solar sail system-level technology through ground testing and the development of subsystems, operations tools, and computational models. Table 1 lists the major SSP activities conducted since the project's inception. 
TABLE 1. Solar sail propulsion tasks

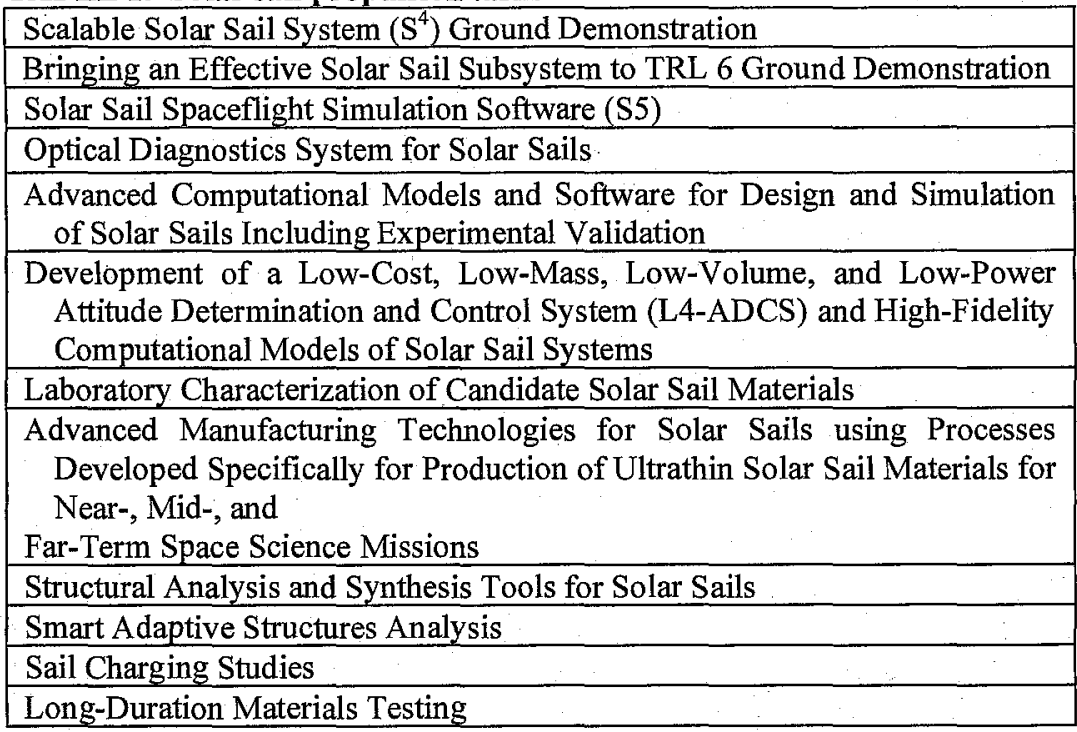

\section{FIRST STEPS}

\section{System-Level Ground Demonstration}

Early in the project, In Space Propulsion funded the development of a prototype solar sail system for ground testing that would be used to validate design concepts for: sail manufacturing, packaging, launch to space and deployment; attitude control subsystem function; and to characterize the structural mechanics and dynamics of the deployed sail in a simulated space environment. A square sail configuration consisting of a reflective sail membrane, a deployable sail support structure, an attitude control subsystem, and all hardware needed to stow the sail for launch were developed. In addition, this system was required to meet the characteristics given in Table 2 , columns 1 and 2. A sub-L1 solar monitoring mission concept was also provided as a reference mission for guidance in design and scalability issues, and is summarized in Table 3. 
TABLE 2. System-level solar sail ground demonstration reporting metrics

\begin{tabular}{|c|c|c|c|}
\hline Metric & RFP & ATK & - L'Garde \\
\hline Dimensions & $\begin{array}{c}20 \mathrm{~m} \times 20 \mathrm{~m} \\
\text { or greater }\end{array}$ & $\begin{array}{l}\text { 20-m system with } \\
\text { flightlike central } \\
\text { structure } \\
\text { - } 4 \text { sails scaled from } 80 \mathrm{~m} \\
\text { - Truncated } 80-\mathrm{m} \text { masts } \\
\text { - Central structure scaled } \\
\text { from } 40 \mathrm{~m}\end{array}$ & $\begin{array}{l}\text { - } 19.5 \text {-m due to } \\
\text { Plumbrook } \\
\text { - } 1 \text { subscale TVCAD vane } \\
\text { - Nonflight central } \\
\text { structure scaled for } 100 \text { - } \\
\text { m system } \\
\text { - Sails and mast truncated } \\
100 \text {-m system }\end{array}$ \\
\hline $\begin{array}{l}\text { Sail Subsystem } \\
\text { Areal Density }\end{array}$ & $\begin{array}{c}<20 \mathrm{~g} / \mathrm{m}^{2} \\
\text { (scalability to } \\
12 \mathrm{~g} / \mathrm{m}^{2} \text { for } \\
104 \mathrm{~m}^{2} \text { ) }\end{array}$ & $\begin{array}{l}\text { - } 112 \mathrm{~g} / \mathrm{m}^{2} \text {, includes } \\
\text { spacecraft bus structure, } \\
\text { ACS, power, instrument } \\
\text { boom } \\
\text { - Scaled to } 11.3 \mathrm{~g} / \mathrm{m}^{2} \text { for } \\
100-\mathrm{m} \text { design and no } \\
\text { payload }\end{array}$ & $\begin{array}{l}\text { - } 30 \mathrm{~g} / \mathrm{m}^{2}, \text { includes ACS } \\
\text { (4 vanes calculated), } \\
\text { central structure } \\
\text { dropped } \\
\text { - Scaled to } 14.1 \mathrm{~g} / \mathrm{m}^{2} \text { with } \\
50-\mathrm{kg} \text { payload and } 41.4- \\
\mathrm{kg} \text { bus }\end{array}$ \\
\hline Stowed Volume & $\begin{array}{c}<0.5 \mathrm{~m}^{3} \\
\text { (scalability to } \\
1.5 \mathrm{~m}^{3} \text { for } \\
104 \mathrm{~m}^{2} \text { ) }\end{array}$ & $\begin{array}{l}-0.9 \mathrm{~m}^{3} \text { scaled to } 1.5 \mathrm{~m}^{3} \\
\text { for } 100-\mathrm{m} \text { design }\end{array}$ & $\begin{array}{l}2.14 \mathrm{~m}^{3} \text { scaled to } 1.04 \\
\mathrm{~m}^{3} \text { for } 100-\mathrm{m} \text { design }\end{array}$ \\
\hline $\begin{array}{l}\text { Thrust Vector } \\
\text { Turning Rate } \\
\text { About Roll Axis } \\
\end{array}$ & $>1.5^{\circ} / \mathrm{hr}$ & $->35^{\circ}$ maneuver in $2 \mathrm{hr}$ & - $63^{\circ} / \mathrm{hr}\left(0.0175^{\circ} / \mathrm{sec}\right)$ \\
\hline $\begin{array}{l}\text { Effective Sail } \\
\text { Reflectance }\end{array}$ & $>0.75$ & - $92 \%$ over solar spectrum & - 85.9 \\
\hline $\begin{array}{l}\text { AntiSunward } \\
\text { Emissivity }\end{array}$ & $>0.30$ & - 0.30 for 3 micron film & - 0.40 \\
\hline $\begin{array}{l}\text { Membrane } \\
\text { Characteristics }\end{array}$ & $\begin{array}{l}\text { Space- } \\
\text { durable, tear- } \\
\text { resistant, } \\
\text { designed for } \\
1 \text { year in the } \\
\text { near-GEO } \\
\text { environment }\end{array}$ & $\begin{array}{l}\approx 2 \text {-micron CP1 with } \\
1000 \text { A of aluminum on } \\
\text { front, bare CP1 on back } \\
\text { of sail. All materials have } \\
\text { space flight heritage. }\end{array}$ & $\begin{array}{l}2 \text { micron Mylar with } \\
1,000 \mathrm{~A} \text { of aluminum on } \\
\text { front and } 200 \mathrm{~A} \\
\text { blackened chromium on } \\
\text { back }\end{array}$ \\
\hline System Flatness & $\begin{array}{l}\text { Effective for } \\
\text { propulsion }\end{array}$ & $\begin{array}{l}\text { - 3-point quadrant support } \\
\text { with shear compliant } \\
\text { border to insure a flat } \\
\text { sail, with a proper stress } \\
\text { level to obtain local } \\
\text { flatness. }\end{array}$ & - Stripped net loss $\approx 2 \%$ \\
\hline ACS & $\begin{array}{c}\text { Three-axis, } \\
\text { minimize } \\
\text { propellant } \\
\text { usage }\end{array}$ & $\begin{array}{l}\text { Sliding trim control mass } \\
\text { on truss and tip bars to } \\
\text { pinwheel quadrants for } \\
\text { roll. Micro PPT backup. }\end{array}$ & $\begin{array}{l}\text { Totally propellantless using } \\
\text { four tip vanes }\end{array}$ \\
\hline
\end{tabular}


TABLE 3. Design reference mission

\begin{tabular}{|c|c|c|c|c|c|c|c|c|}
\hline $\begin{array}{l}\text { Launch } \\
\text { Mass } \\
(\mathbf{k g})\end{array}$ & $\begin{array}{c}\text { Payload } \\
\text { Mass } \\
(\mathbf{k g})\end{array}$ & $\begin{array}{c}\text { Payload } \\
\text { Power } \\
(\mathbf{W})\end{array}$ & $\begin{array}{c}\text { Total } \\
\text { Power } \\
(\mathbf{W})\end{array}$ & $\begin{array}{c}\mathbf{T M} \\
\mathbf{D i s h} \\
(\mathbf{m})\end{array}$ & $\begin{array}{c}\mathbf{T M} \\
\mathbf{T M}\end{array}$ & $\begin{array}{c}\text { Rate } \\
\mathbf{( K b} / \mathbf{s})\end{array}$ & $\begin{array}{c}\text { S/C } \\
\text { Dia. } \\
(\mathbf{m})\end{array}$ & $\begin{array}{c}\text { Launch } \\
\text { Vehicle }\end{array}$ \\
\hline 250 & 50 & 100 & 750 & 1.5 & $\mathrm{X}$ & 100 & $<2.3$ & $\begin{array}{c}\text { Delta } \\
2425-9.5\end{array}$ \\
\hline
\end{tabular}

SSP awarded ground demonstration contracts to two companies that proposed two separate types of technologies in order to achieve the project objective. ABLE Engineering Company's (now ATK Space Systems) proposed work based on their prior New Millennium Program (NMP) ST-7 proposal, incorporating their rigid coilable boom, an articulating boom attitude control system (ACS) subsystem and partner SRS' CP1 sail membrane. L'Garde, Inc. proposed work based on the experience they gained on an NMP ST-5 proposal and as the sail provider for Team Encounter, incorporating their inflatable and sub-Tg rigidizable boom, a control vanebased ACS and Mylar for the sail membrane. The parallel testing and development of these two system level demonstrations that have varied technologies in the three major components removed the risk to this technology development if one provider encountered an unrecoverable failure. The system-level ground demonstration work was divided into three phases. A 6-month concept refinement phase was completed in May 2003. During this phase, the two teams provided analysis of their system's performance when scaled to the design reference mission and a preliminary test plan for the following two 12-month phases. The 12-month hardware development phase began in June 2003. In this phase, both teams built and tested components and subsystems, with ATK concentrating on a single 10-meter quadrant and L'Garde developing a 10-meter square sail. The most comprehensive of these tests occurred in the middle of 2004 when the respective teams deployed their integrated subsystem in the Langley Research Center (LaRC) 14-meter vacuum facility (ATK) and the 30meter vacuum chamber at Glenn Research Center's Plum Brook Space Power Facility (L'Garde). Following a successful second phase, the teams culminated their work in a 12-month system verification phase. In this phase, both teams built and tested fully integrated 20-meter sail systems that included a launch packaging container and operational ACS subsystems. In the middle of 2005, the respective teams tested their system in the Plum Brook Facility under a high vacuum and appropriate thermal environment, as well as subjecting their systems to launch vibration and ascent vent tests. Figures 1 and 2 show the 20-meter deployed systems at the Plum Brook Facility. Table 2, columns 3 and 4, summarizes the final metrics achieved by ATK and L'Garde with their 20-meter systems. Since these sails represent the largest systems that will be tested in a vacuum chamber on the ground, a significant effort was made to collect static and dynamic data on the sails and booms with $\approx 400 \mathrm{~Gb}$ of data collected, primarily raw photogrammetry data. Technical descriptions of work being performed by AEC [1-4] and L'Garde [5-7] on the 20-meter ground system demonstrator can be found in the respective team's papers. 


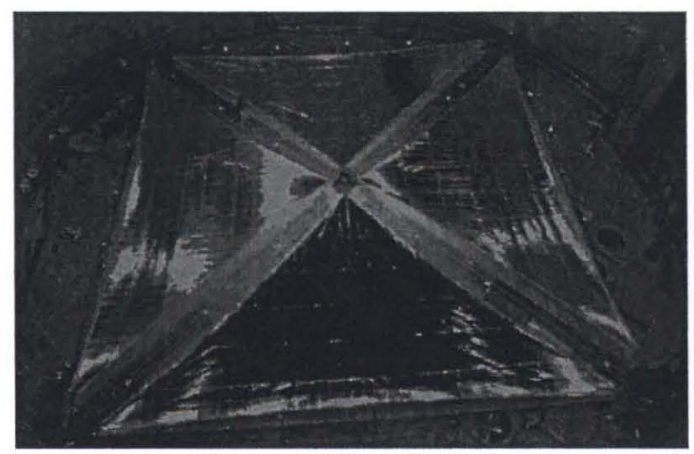

FIGURE 1. ATK 20-meter SG D

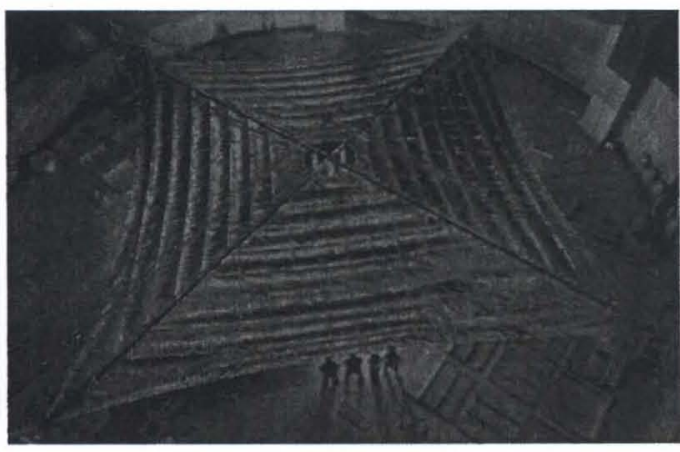

FIGURE 2. L'Garde 20-meter S G D

\section{Solar Sail Integrated Software Tools}

ISPT then funded a set of integrated simulation tools to predict the trajectory, maneuvers, and propulsive performance of a solar sail during a representative flight profile. The solicitation encouraged that these tools should be able to be integrated into an optimal guidance, navigation, and control subsystem on a future flight mission. In addition, the tools were required to be applicable to a solar sail mission of characteristics given in Table 3 and incorporate the following analytical models:

- Solar radiation pressure acting on the sail as a function of sail orientation and distance from the Sun.

- Disturbance forces acting on the sail such as gravitational torques and thermal deformation of the support structure.

- Orbital mechanics.

- Sail structural dynamics.

- ACS dynamics.

- Navigational sensors.

The Solar Sail Spaceflight Simulation Software (S5) incorporated a 6-month Phase 1 that was completed in September 2003, with Phase 2 completed in July 2004, and Phase 3 completed in February 2006. At the end of Phase 3, of the 173 requirements specified in the S5 Software Requirements Document, 66 were fully implemented and integrated into the S5 system and 50 were partially integrated into the system or fully implemented in a standalone code. See reference [8] for a discussion of the S5 software and recent validation efforts. 


\section{MIDPROGRAM DEVELOPMENTS}

\section{Optical Diagnostic System}

The overall objective for this task was the development of an optical diagnostic system (ODS) to Technology Readiness Level (TRL) 6 for a solar sail. Possible requirements for the ODS included observation of the sail deployment and monitoring of the health and integrity of the sail during and after deployment. After solar sail deployment, the ODS would be available to provide shape and vibration measurements adequate to infer the stress state of the solar sail by aid of computational structural models which could then feed real time into a closed-loop spacecraft guidance and control system. The initial 6-month base period included concept development preceded by definition of the goals, priorities, and requirements for the ODS [9]. It was determined that continuous real-time integration with the guidance system was not necessary due to the quasi-steady-state nature of solar sail operations. In addition, studies by Zeiders [10] and Ewing [11], showed the relative insensitivity of the thrust vector magnitude and direction to sail billow. The conceptual design process identified a number of significant challenges to on-orbit photogrammetry including significant weight, power, and data requirements for instruments and support structures for camera clusters, achieving sufficient image contrast, integrating targets into the sail membrane, and considerable software development needs. The concept development activities were conducted in parallel with the development of the ground test capability for the solar sail demonstrator hardware. A developmental test of an L'Garde inflatable boom in a thermal vacuum chamber at Goddard Space Flight Center, as well as tests on smaller sail quadrants [12], provided an opportunity to familiarize researchers with cameras, analytical tools, and test operations. Building on this experience and adding capabilities for dynamic excitation and laser vibrometry, imaging, and a "truth" instrument, the ATK 10-meter demonstrator testing was performed in the 16-meter vacuum chamber at LaRC. These activities formed the foundation for the test methods and instrumentation employed in the final 20-meter demonstrations tests. An exceptional team of photogrammetry experts from LaRC, working in conjunction with the contractor test teams, were successful in acquiring both static and dynamic deflection data in a number of various thermal and vacuum conditions and system configurations despite tremendous difficulties that arose. For example, condensate "rain" fell on the test article as the huge Plum Brook chamber was pumped down, causing boom tip positions to change so much that complex, remotely operated, adjustable instrument platforms had to be devised. A tremendous volume of data was required to provide high-resolution measurements over 400 square meters of area and data collection was made difficult by the clean aluminum walls and floor of the chamber, which provide little natural contrast to the aluminized sails. Finally, the cost of operations in such a large chamber is not inconsiderable. The teams were constantly under the gun to debug problems, acquire data, and assess data quality quickly with limited hands on the equipment and only a few pump-downs allowed. The difficulty of photogrammetry was not insurmountable, but it did indicate the challenges identified in the conceptual design phase were real. Combined with a 
better understanding of the lack of a need for on-orbit photogrammetry, the further development of a flight system was not pursued.

\section{Advanced Computational Methods}

To address the concern that conventional finite element models might be inadequate to evaluate solar sails, a phased approach to address the structural design issue was pursued. The first relied on the prime contractors to apply standard practices using the existing state of the art. As part of the ground system demonstrations, finite element analyses (FEAs) were created by LaRC, ATK, and L'Garde of the 10-meter systems using both commercial off-the-shelf and custom software. These models did not always converge and were computationally intensive, but no more so than is experienced in typical spacecraft design. The purpose of this task was to create methods/algorithms/techniques that improved the conventional FEA of the membranes, booms, and other subsystems. Several methods were identified, but the option phases to complete and validate them were not funded due to the success of the prime contractors in modeling the 20-meter systems with conventional techniques, thus lowering the priority of this task below the level of the available funding.

\section{Structural Analysis and Synthesis Tools}

This task also addresses the structural analysis issue by developing from the ground up, new and unconventional modeling techniques. Techniques considered included direct transfer function modeling (DTFM) and parameter variation processing (PVP). The overall objectives for this task were completion of DTFM modeling/analysis methods for long booms, completion of capability to evaluate effects of imperfections, completion of PVP method for analyzing wrinkled membranes, and completion of test/analysis correlation by using existing test data. As in the above task, this effort was terminated prior to completion due to success using conventional modeling methods with the 20 -meter systems and a lack of funding.

\section{Lightweight Attitude Control System}

The objectives of this 2-year project were (1) to design, integrate, and test a sail attitude control system (SACS) employing a two-axis gimbaled control boom and (2) to develop a high-fidelity, multiflexible body model of ATK's solar sail for the purpose of validating a thrust vector control (TVC) concept employing a two-axis gimbaled control boom. One of the major findings from this study was that the two axis gimbaled control boom was not a mass efficient method of controlling a solar sail [13]. A more efficient method was derived based on an offset mass moved along the booms by a clothesline-like apparatus to control pitch and yaw and rotating stabilizer bars at the sail tips to pinwheel the sail quadrants for roll control. This finding led to a major redesign of the ATK 20-meter hardware to accommodate the new TVC concept. An attitude determination and control block diagram was derived to present the appli- 
cation/integration of the inertial stellar compass with a range of ACS options from $\mathrm{cp} / \mathrm{cm}$ offset to pulsed plasma microthrusters [14].

\section{Characterization of Solar Sail Materials}

The purpose of this task was to conduct laboratory characterization of several candidate solar sail materials. The space radiation and micrometeoroid environments for 1.0 (Heliostorm) and 0.5 (SPI) astronomical units missions were defined and candidate materials were tested against these radiation and meteoroid environments. Through a series of learning tests, the sample holddown designs was optimized and a flexure test developed. Several samples of the SRS and L'Garde membrane materials were tested by subjecting them to gigarad levels of radiation-in simulations of long-duration solar wind mission types [15]. While some of the samples showed significant levels of degradation in mechanical strength, solar sail loading is so low that very little strength is needed.

\section{Advanced Manufacturing Technologies for Solar Sails}

The purpose of this task was to investigate and develop an integrated approach to ultrathin film solar sail manufacturing. The focus was on improving coating processes and technologies; developing sail seaming technologies for large monolithic sails; providing an integrated approach to membrane coating, acceptance, assembly and integration; and integrating future improvements (such as electrospun nanofibers for ripstop enhancement without added mass and the addition of carbon black nanotubes to the sail backside to increase emissivity) [16] into the process. The final results of this 2-year effort are the development of a scroll coating system, the development of coating capabilities of $<2.5$ microns, and the development of a membrane seaming system able to form monolithic sails with coatings at least as thin as 2.5 microns.

\section{FILLING THE GAPS}

\section{Smart Adaptive Structures}

In order to mature the TRL of solar sail propulsion, advancements must be made in the pointing and dynamical control of these large space structures. This tasks' objective was to develop and verify structural analytical models, develop structural scaling laws, and develop adaptive control laws for solar sails to be verified on a $>30$-meter vertically supported boom. In the summer of 2006, a closed-loop boom controller will be demonstrated.

\section{Charging in Space Environment}

Due to two extreme characteristics of future solar sail missions, the large surface area of the sail and the long-duration of potential missions, typical spacecraft charging issues will be exacerbated. The purpose of this task was to characterize charged particle environments for analyzing solar sail charging in the solar wind and at geostation- 
ary orbit and to model surface and internal electric fields and potentials for solar sails using existing spacecraft charging models. Solar sail materials were tested in simulated charging environments to determine permeability and charge retention properties. The task was completed March 1, 2006. A significant finding was that there will be very little charging of the sail surfaces, $\approx 10$ volts as a worst case in sunlight. The study found that problems arise if the sail material backing is non-conductive or electrically decoupled from the front surface. In that case, the shadowed back surface can reach potentials of -30 to -40 volts relative to the space plasma in the solar wind-on the order of arcing onset potentials. The solution is to make sure the sail material is conductive front to back and end to end if the sail is to be in geosynchronous orbit or in the auroral zone and be very careful with electrically isolated objects in the shadow of the sail [17].

\section{Long-Term Space Environmental Effects}

Critical to the development of Solar Sails is an investigation of space environmental effects on these large thin film materials and the edge support technologies. This task was related to the "Characterization of Solar Sail Materials" task above. The above task used accelerated dose levels over a shorter period of time to simulate the total dose of radiation received by a material for many years. The purpose of this task was to provide critical thermal, optical, mechanical, and surface data on large sails taking into account edge stresses and edge support technologies that can only be characterized using large size sails but not at accelerated levels. These resulting test data could be used to validate the accelerated dose test methodology regarding the durability of candidate sail material (embrittlement, optical, mechanical, surface, and thermal properties). This task was recommended by the 2004 Technology Assessment Group.

\section{SRS Solar Sail Propulsion Evaluation Tool}

This 16-week study provided a better understanding of the impacts of nonideal sail characteristics to support further solar sail development. This study was divided into three tasks. Task 1 was Integrated Optical Design Analysis (IODA) Software Modification to support solar sail propulsion analysis. The objective of the sail analysis model was to provide a detailed calculation of the thrust vector magnitude, direction, and center of pressure based on the predicted shape of the sail and the sail optical properties including reflectivity, emissivity, and specularity. The program also calculated the torques applied to the vehicle using the thrust vector, center of pressure, and vehicle center of mass. Task 2 was for the development of models to characterize the total momentum transfer imparted to a sail element (including the contributions from thermal emissions and diffuse reflections). Task 3 was software testing, including at least one FEM to be used for testing the software, demonstration of the software using any additional NASTRAN or ALGOR FEM models provided, and delivery of a Beta test version of the modeling software for evaluation by government personnel. 


\section{FUTURE DIRECTIONS}

The SSP Project approach of providing near term verification of solar sails through the development of system level technology using ground testing and the development of subsystems, operations tools and computational models has begun building a technological foundation that can be readily used by future programs, including The Interstellar Probe.

\section{ACKNOWLEDGMENTS}

The work described in this paper was funded in whole or in part by the In-Space Propulsion Technology Program, which is managed by NASA's Science Mission Directorate in Washington, D.C., and implemented by the In-Space Propulsion Technology Project at Marshall Space Flight Center in Huntsville, AL. The program objective is to develop in-space propulsion technologies that can enable or benefit near and mid-term NASA space science missions by significantly reducing cost, mass or travel times. 


\section{REFERENCES}

1. D. Murphy, "Validation of A Scalable Solar Sailcraft," $53^{\text {rd }}$ JANNAF Propulsion Meeting, December 2005

2. J. Gaspar et al., "Testing Of A 20-Meter Solar Sail System," $53^{\text {rd }}$ JANNAF Propulsion Meeting, December 2005.

3. B. Taleghani et al, "20 Meter Solar Sail Analysis And Correlation," $53^{\text {rd }}$ JANNAF Propulsion Meeting, December 2005.

4. G. Laue, D. case, J. Moore, "Fabrication and Deployment Testing of Solar Sail Quadrants for a 20meter Solar Sail Ground Test System Demonstration," 41st ALAA Joint Propulsion Conference, July 2005, AIAA 2005-3930.

5. D. Lichodziejewski et al., "Vacuum Deployment and Testing Of a $20 \mathrm{~m}$ Solar Sail System," $47 \mathrm{th}$ AIAA/ASME/ASCE/AHS/ASC Structures, Structural Dynamics, and Materials Conference, May 2006, AIAA 2006-1705.

6. D. Sleight et al., "Structural Analysis and Test Comparison of a 20-Meter Inflation-Deployed Solar Sail," 47th AIAA/ASME/ASCE/AHS/ASC Structures, Structural Dynamics, and Materials Conference, May 2006, AIAA 2006-1706.

7. T. Mann et al., "Ground Testing A 20-Meter Inflation Deployed Solar Sail," 47th AIAA/ASME/AS.CE/AHS/ASC Structures, Structural Dynamics, and Materials Conference, May 2006, AIAA 2006-1707.

8. J. Ellis et al., "A Solar Sail Integrated Simulation Toolkit," Proc. AAS/AISS Spaceflight Mechanics, Maui, HI, Feb. 2004, AAS 04-283.

9. R. Pappa et al., "Optical Diagnostic System for Solar Sails: Phase 1 Final Report," NASA/TM2004-213511, Dec. 2004.

10. G. Zeiders, "Design Rules and Scaling for Solar Sails," 41st AIAA Joint Propulsion Conference, July 2005, AIAA $2005-4553$.

11. A. Ewing, "Solar Sail Propulsion Sensitivity to Membrane Shape and Optical Properties Using the Solar Vectoring Evaluation Tool (SVET)," 53rd JANNAF Propulsion Meeting, December 2005.

12. J. Black and R. Pappa, "Photogrammetry and Videogrammetry Methods for Solar Sails and Other Gossamer Structures," 45th AIAA/ASME/ASCE/AHS/ASC Structures, Structural Dynamics and Materials Conference, April 2004, AIAA 2004-1662.

13. D. Murphy and B. Wie, "Robust Thrust Control Authority for A Scalable Sailcraft," Proc. AAS/AISS Spaceflight Mechanics, Feb. 2004, AAS 04-285.

14. S. Thomas, M. Paluszek, B. Wie, D. Murphy, "AOCS Performance and Stability Validation for a 160-m Solar Sail with Control-Structure Interactions," 41st AlAA Joint Propulsion Conference, July 2005, AIAA 2005-3926.

15. D. Edwards, et al., "Characterization of Candidate Solar Sail Material Exposed to Space Environmental Effects," 42nd AIAA Aerospace Sciences Meeting and Exhibit, Jan. 2004, AIAA 2004-1085.

16. C. Talley, W. Clayton; P. Gierow; J. McGee, J. Moore, "Advanced Membrane Materials for Improved Solar Sail Capabilities," 43rd AIAA/ASME/ASCE/AHS/ASC Structures, Structural Dynamics, and Materials Conference: 3rd AIAA Gossamer Spacecraft Forum, April 2002, AIAA 2002-1561.

17. H. Garrett and J. Minow, "Charged Particle Effects on Solar Sails Final Report," NASA TM (to be published). 


\section{Status of Solar Sail Propulsion: Moving Toward An Interstellar Probe.}

Les Johnson Roy M. Young Edward E. Montgomery iv August 2006. 
- Solar sails use photon "pressure" of force on thin, lightweight reflective sheet to produce thrust; ideal reflection of sunlight from surface produces 9 Newtons $/ \mathrm{km}^{2}$ at $1 \mathrm{AU}$

- Net force on solar sail perpendicular to surface

- One component of force always directed radially outward

- Other component of force tangential to orbit (add/subtract $\mathrm{V}_{\mathrm{o}}$ )

$[<0.2$ oz per football field]

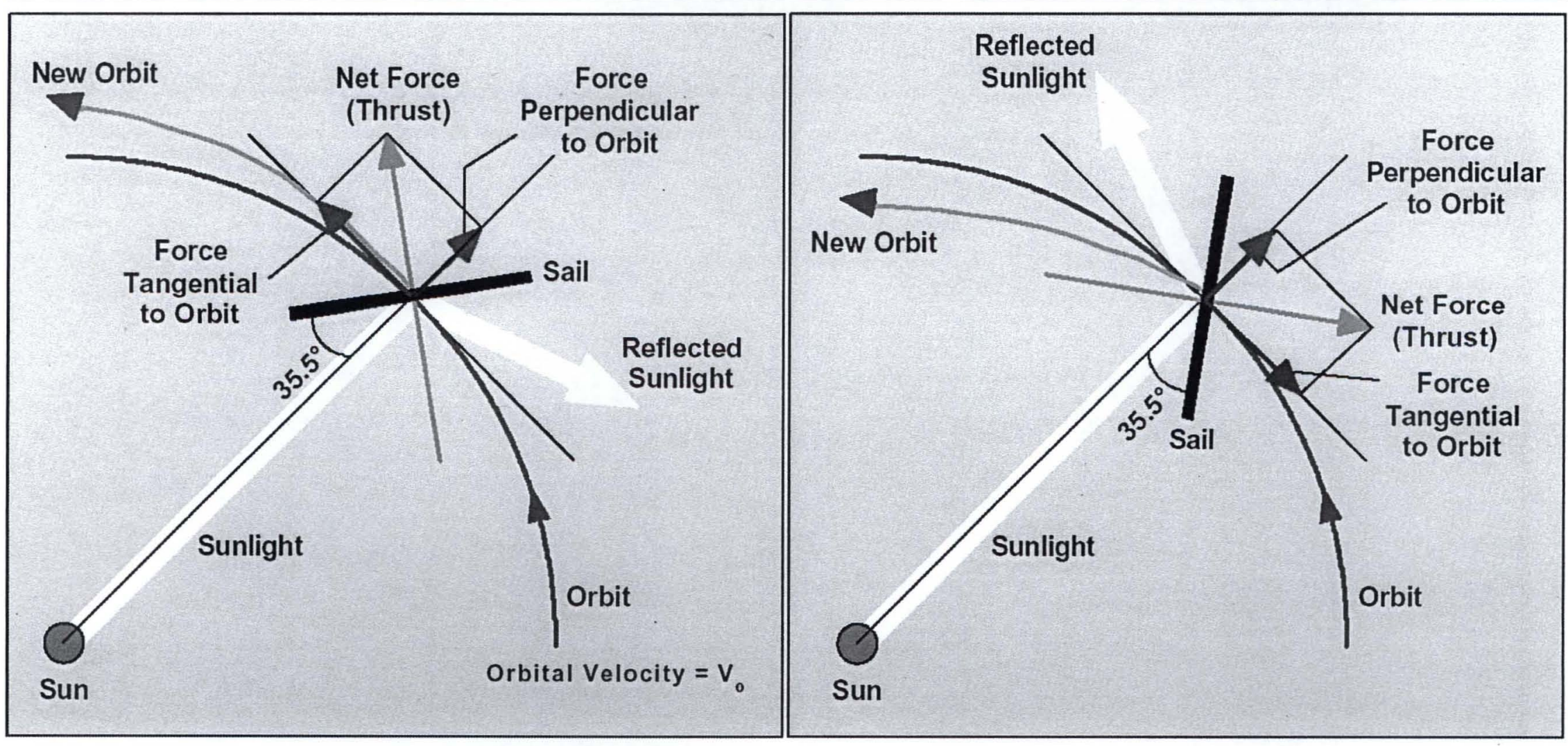

Don’t forget the centripetal term! 


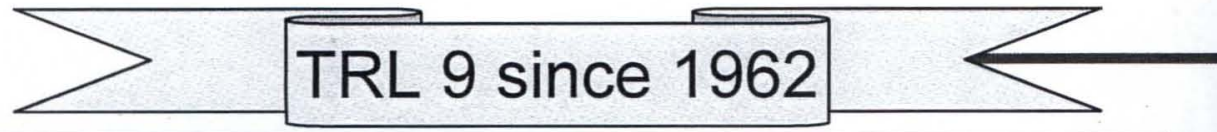

- Solar Sailing was initially developed at JPL as a measure to save the Mariner 10 mission which had lost a large portion of its propellant margin when the star tracker locked on to floating debris instead of Canopus. The mission went on to flyby Venus and three encounters with Mercury. Its successful implementation on that mission led to it being declared a mature technology, ready for application to future NASA missions in 1978.

- $\quad$ Several Comsats (e.g. INSAT 2E) operating today in GEO use solar pressure to unload momentum wheels or offset solar torques on asymmetric solar arrays.

- $\quad$ Chosen for Halley Comet Rendezvous in 1985, it was replaced by a chemical rocket in phase $B$ due to launch date/window pressure

- Japanese

- developing 50 meter sail to combine with an ion thruster for outer planet missions

- Have flown sounding rocket, balloon, and LEO Polar orbit development experiments

- Joint NASA/NOAA/USAF proposal to NMP ST5 fell in the $11^{\text {th }}$ hour when USAF/NASA/NOAA partnership collapsed

- Planetary society launched a flight experiment and a full system on converted Russian Volna sub-launched missiles.

Unfortunately both boosters had stage separation failures.

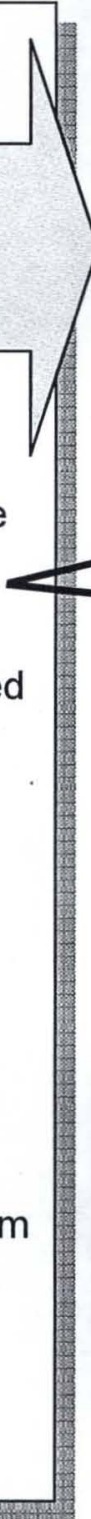

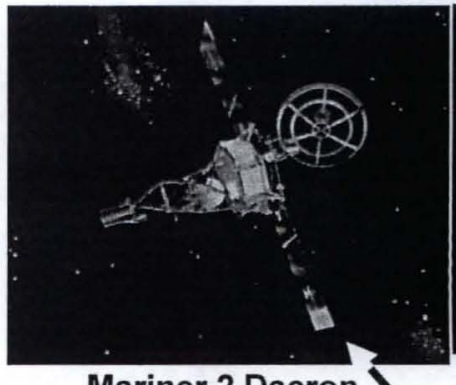

Mariner 2 Dacron Solar Sail (1962)

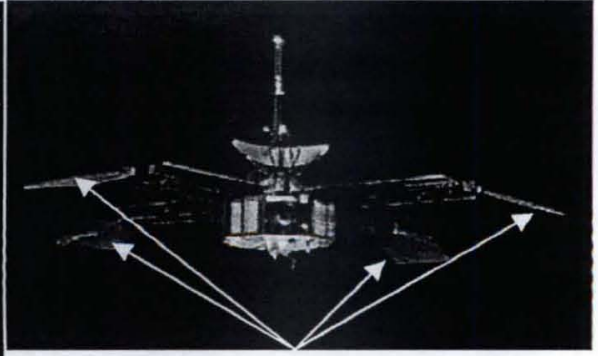

solar sails on Mariner IV (1964)
Mariner 10: "the solar sailing fechnique foreonservation of attitude control gas was impovised successtully ang thereby qualified as a technique for use in future missions. - Bruce page 142

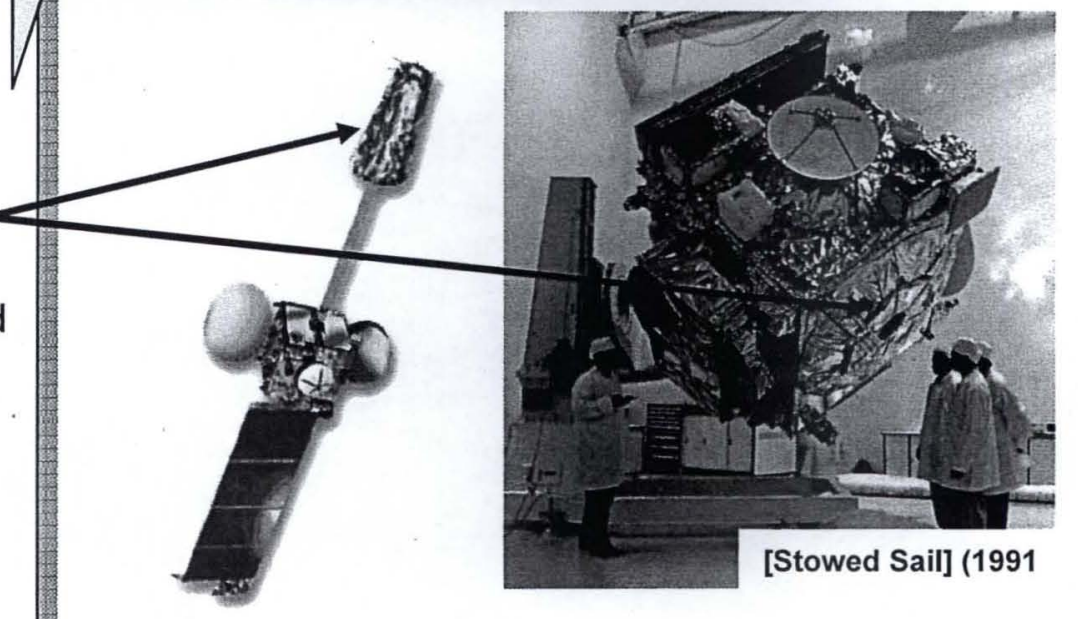




\section{Solar sail Propulsion Technology Advantages}

\section{Low Cost to Develop \& Operate}

- Simple

- Few moving mechanical parts

- Low complexity

- Quasi-Steady State

- Small in size - payloads and stowed system

- Autonomous, robotic
- Safe

- No High temperatures

- No High pressures

- No High Power

- No Toxic fuels

- Loads are vanishingly small
- Technology Benefits

- No propellants required

- Low system complexity (challenge is scaling to large area with ultra-low density)

- Low environmental impact on payload

- Enables access to previously inaccessible orbits (e. g., non-Keplerian, fixed reference, and high inclination orbit changes)
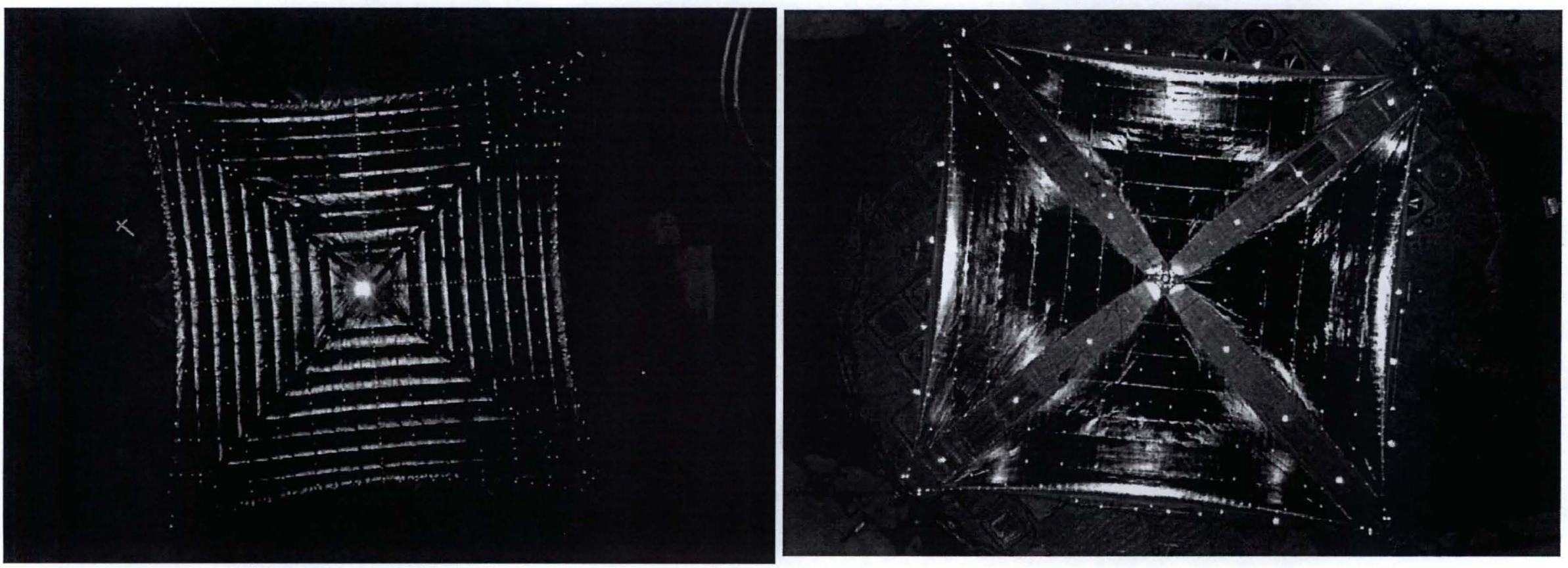


\section{SEC Solar Sail Roadmap}

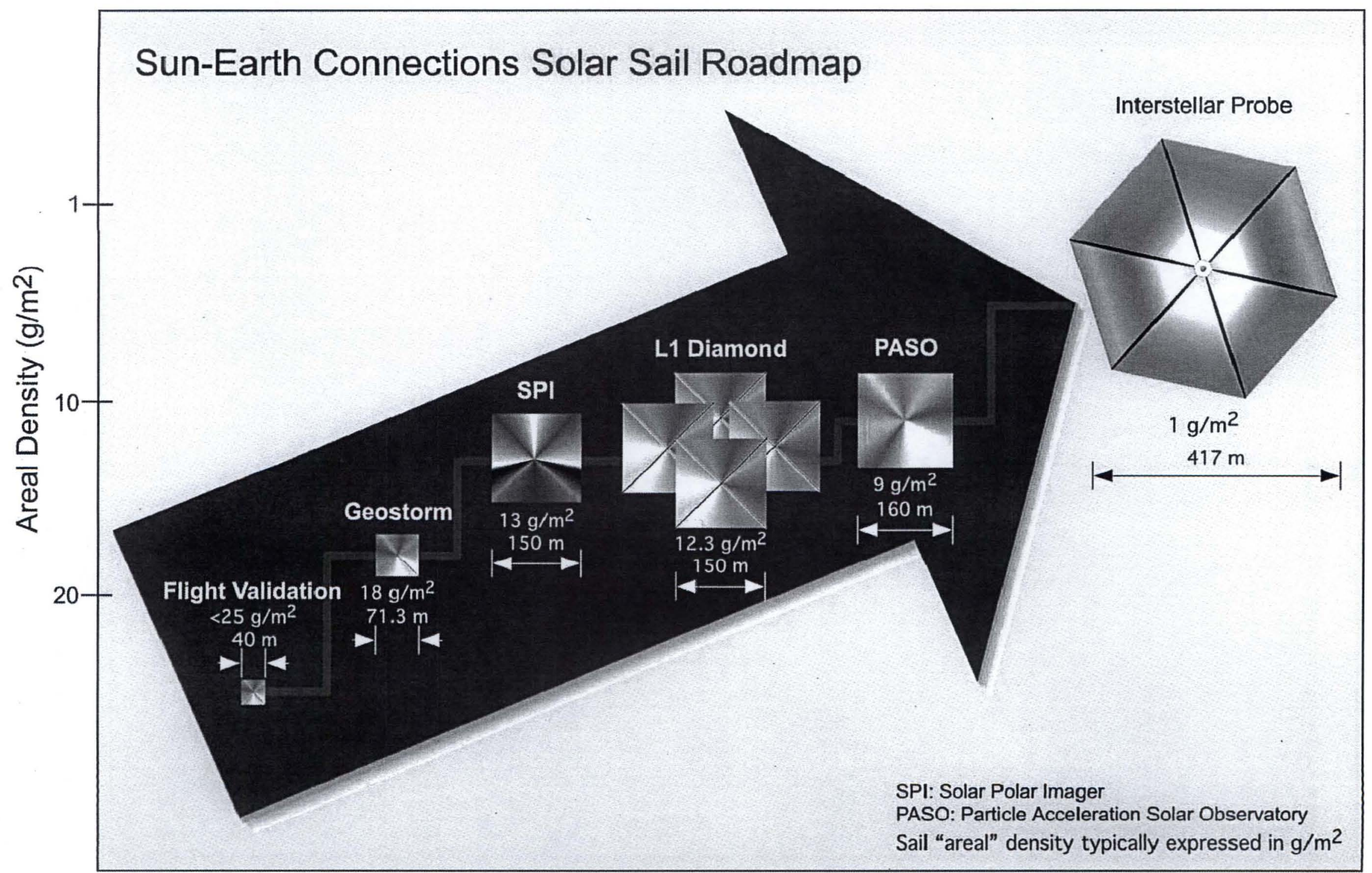

Time 


\section{Heliophysics Draft Roadmap - 5/2006}
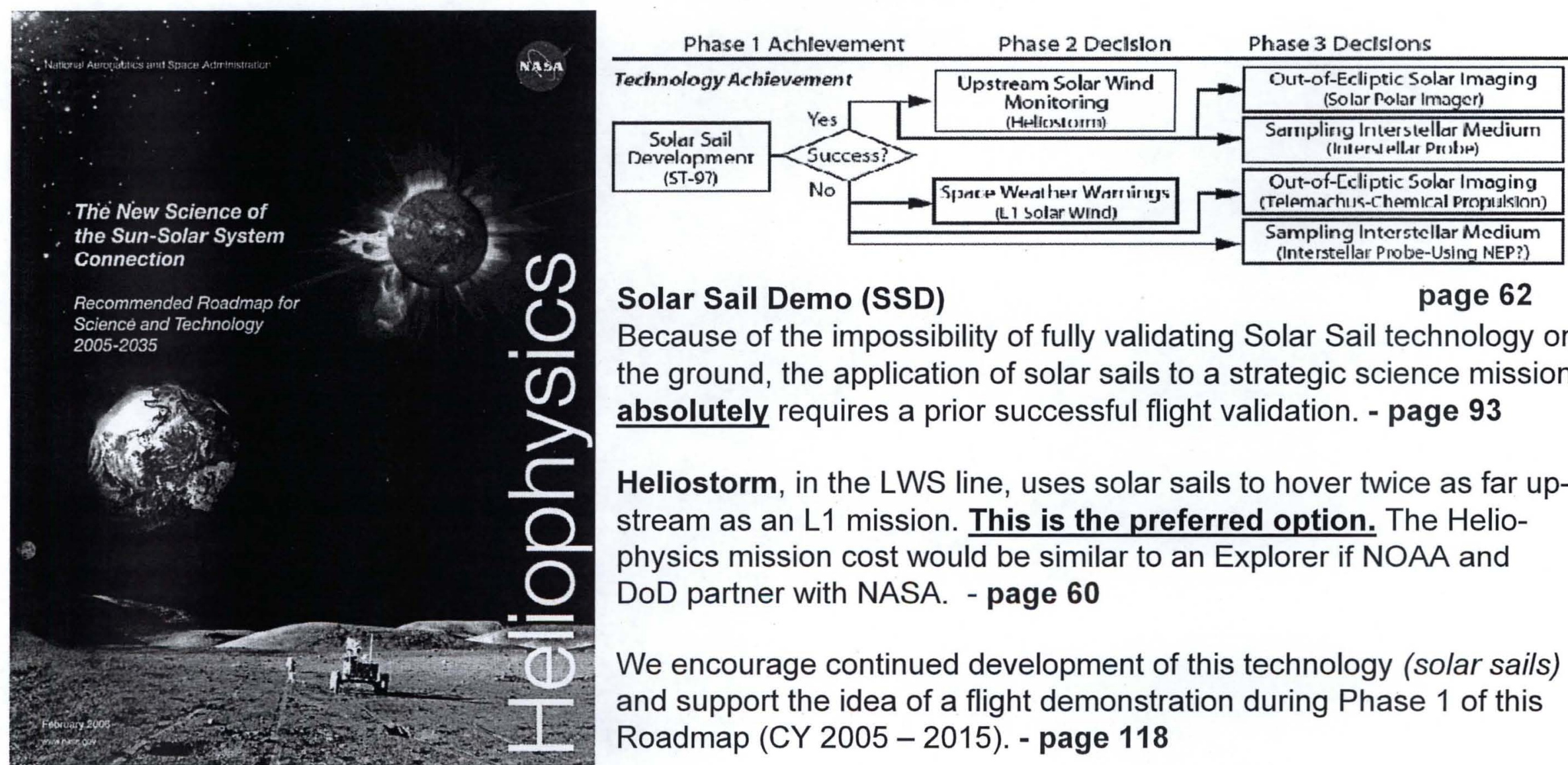

Solar Sail Demo (SSD)

page 62

Because of the impossibility of fully validating Solar Sail technology on the ground, the application of solar sails to a strategic science mission absolutely requires a prior successful flight validation. - page 93

Heliostorm, in the LWS line, uses solar sails to hover twice as far upstream as an L1 mission. This is the preferred option. The Heliophysics mission cost would be similar to an Explorer if NOAA and DoD partner with NASA. - page 60

We encourage continued development of this technology (solar sails) and support the idea of a flight demonstration during Phase 1 of this Roadmap (CY 2005 - 2015). - page 118

Progress in key areas of Heliophysics science requires access to unique vantage points and in some cases, non-Keplerian orbits. For example, imaging of the Sun's polar regions requires a high-inclination, heliocentric orbit. Conventional technology would require either 5 years of solar electric propulsion and multiple Venus flybys just to reach a $38^{\circ}$ inclination in the inner heliosphere (as for ESA's Solar Orbiter) or a Jovian gravity assist and conventional propulsion to provide an eccentric $0.25 \times 2.5 \mathrm{AU}$ polar orbit (as for our future Telemachus mission). Neither means is as efficient or cost effective as solar sail technology. - page 97 


\section{Solar Sail Technology Classes}

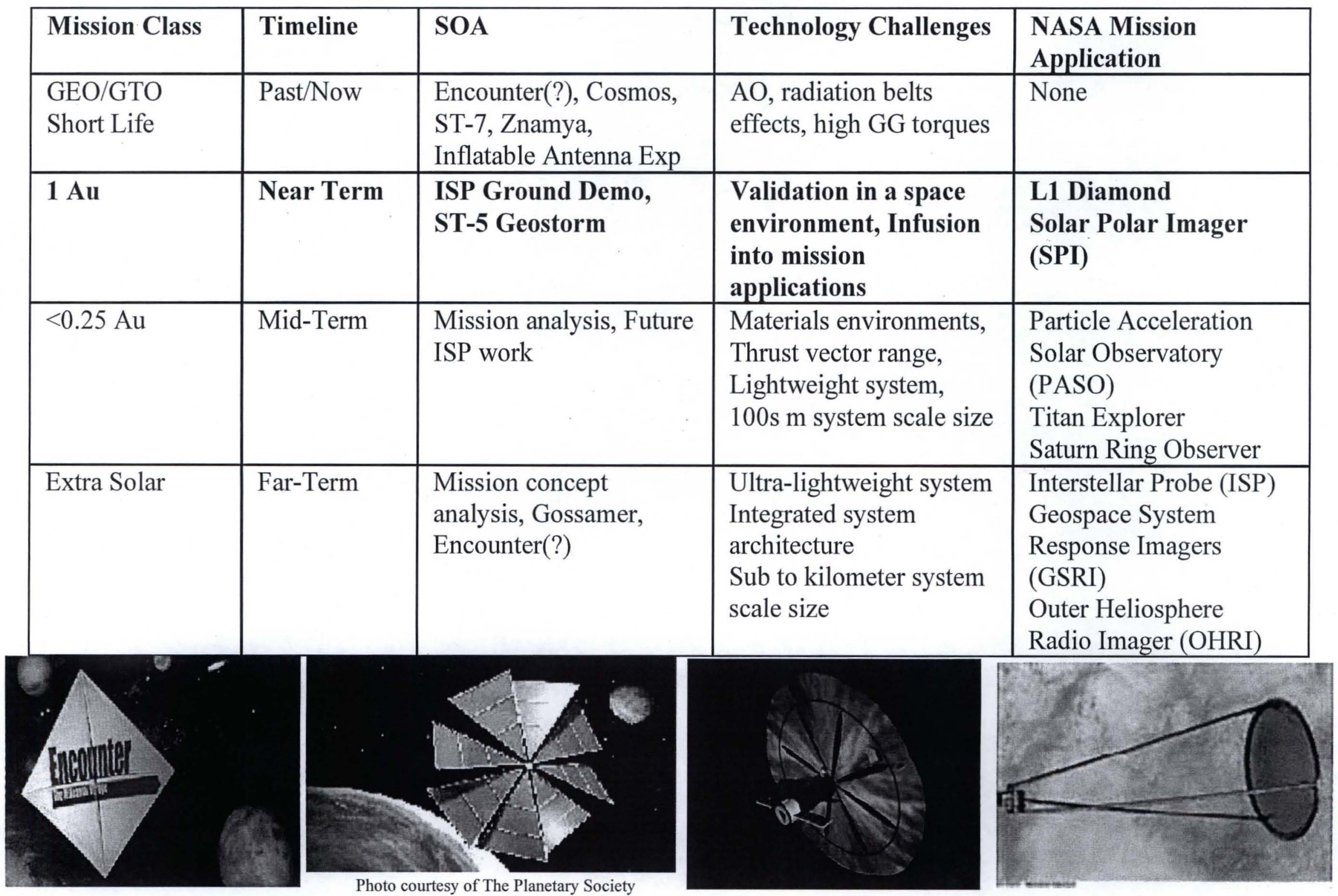




\section{Current Technolog 1 AU Glass

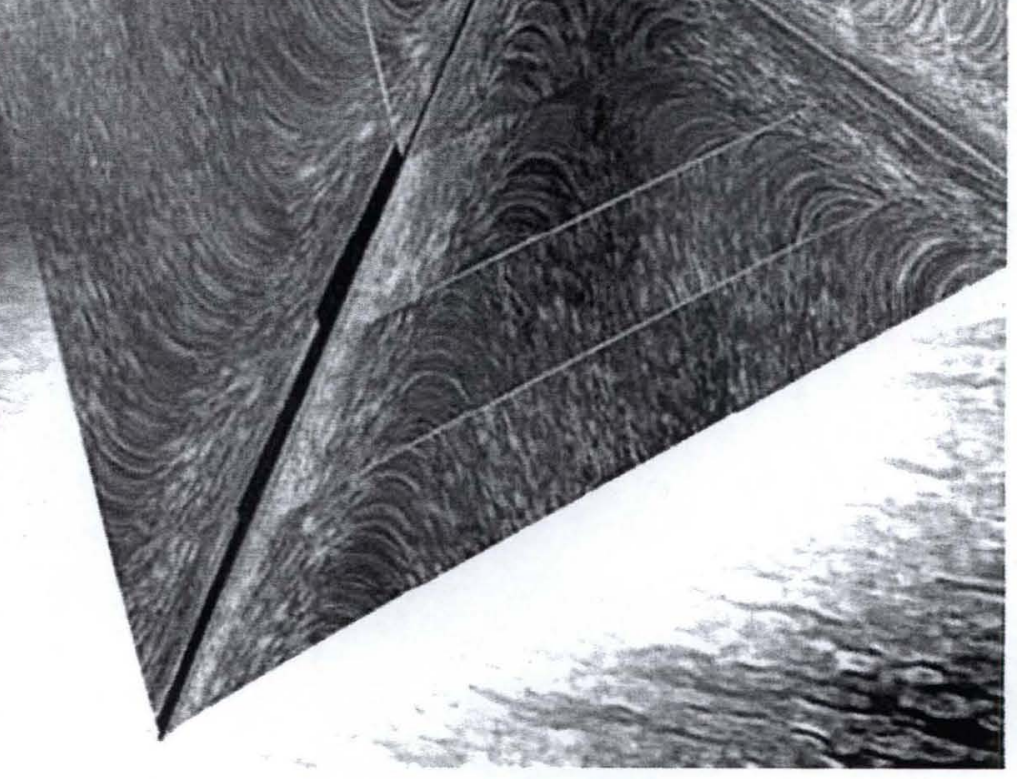

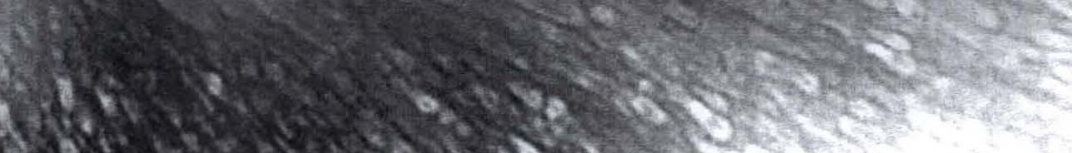

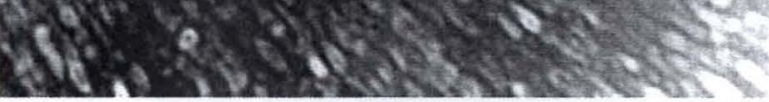


Heliostorm: Advanced Warning

Of Solar Flares 


\section{AU Mission Pull: Heliostorm}

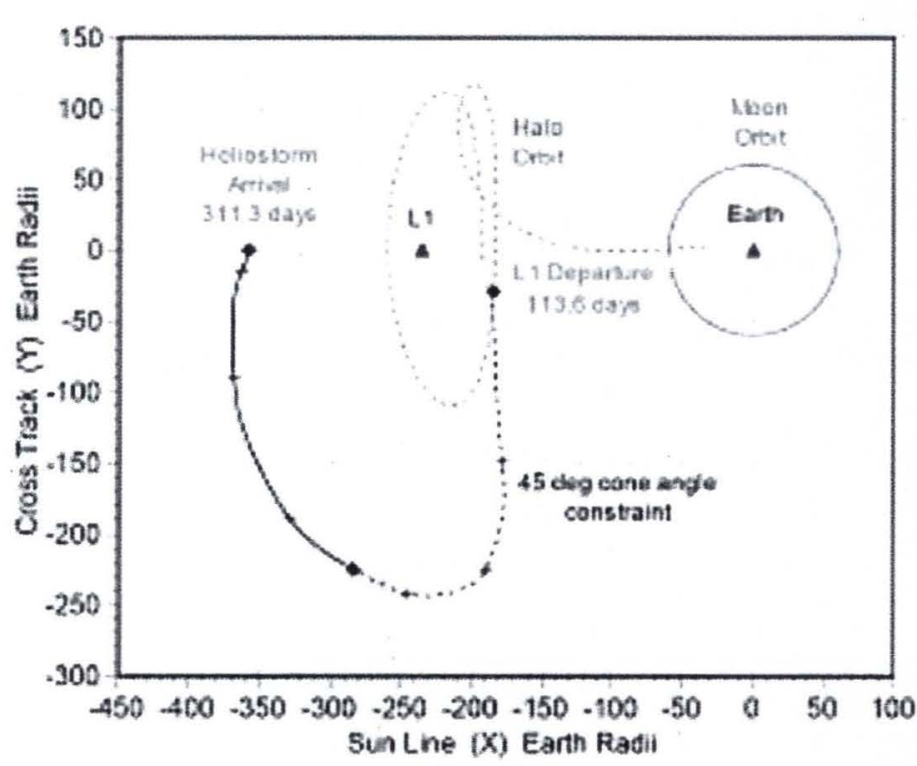

\section{Technology Development}

- Solar Sail: $100 \mathrm{~m}$ edge @ $14.3 \mathrm{~g} / \mathrm{m}^{2}$

- Solar Sail Navigation Tools

- ISP Development Funding

- Autonomous Thrust Vector Control

- "Multi-Chip Module" (MCM) Electronics

- Radiation Tolerant $\mu$-packaged MCMs on 2- $6 \mathrm{U} \mathrm{cPCl}$ cards

\section{Science Objectives}

- Increase by $50-100 \%$ the waming time of CMEs \& shockaccelerated energetic particles for vulnerable lunar, Earth-orbiting, and terrestrial personnel and systems

- Determine the structure of the solar wind on spatial and temporal scales that are relevant for driving magnetospheric processes

- Use solar sail technology to "improve operational observation systems ${ }^{\circ}$

- Provide a pathfinder for the L1-Diamond science mission

\section{Mission Description}

- Example Mission Design

- Delta II Launch Vehicle

- Trajectory: ballistic transfer from Earth to L1 Halo ( 90 days), solar sail transition $\left(a_{\mathrm{c}}=0.21 \mathrm{~mm} / \mathrm{s}^{2}\right)$ from $L 1$ to $\sim 120 \mathrm{R}_{\mathrm{E}}$ Sunward of L1 OPS station

- Continuous Solar Viewing: 2 years In Final Orbit

- Flight System Concept

- Solar-array powered S/C with solar sail

- Payload: Fields and Particles+ Imaging (33 kg/24 W)

\section{Measurement Strategy}

- Plasma/Magnetic Field observations of shock strength provide warning for SEP enhancements for lunar missions and for Earth

- Radio: With other spacecraft, one can triangulate the location of interplanetary shocks

- Energetic particles provide environmental data for lunar missions (although very little warning)

- Optical system provides diagnostics during sail deployment/checkout and heliospheric imaging thereafter

Hellostorm-2 


\section{Solar Sail Propulsion Technology Status}
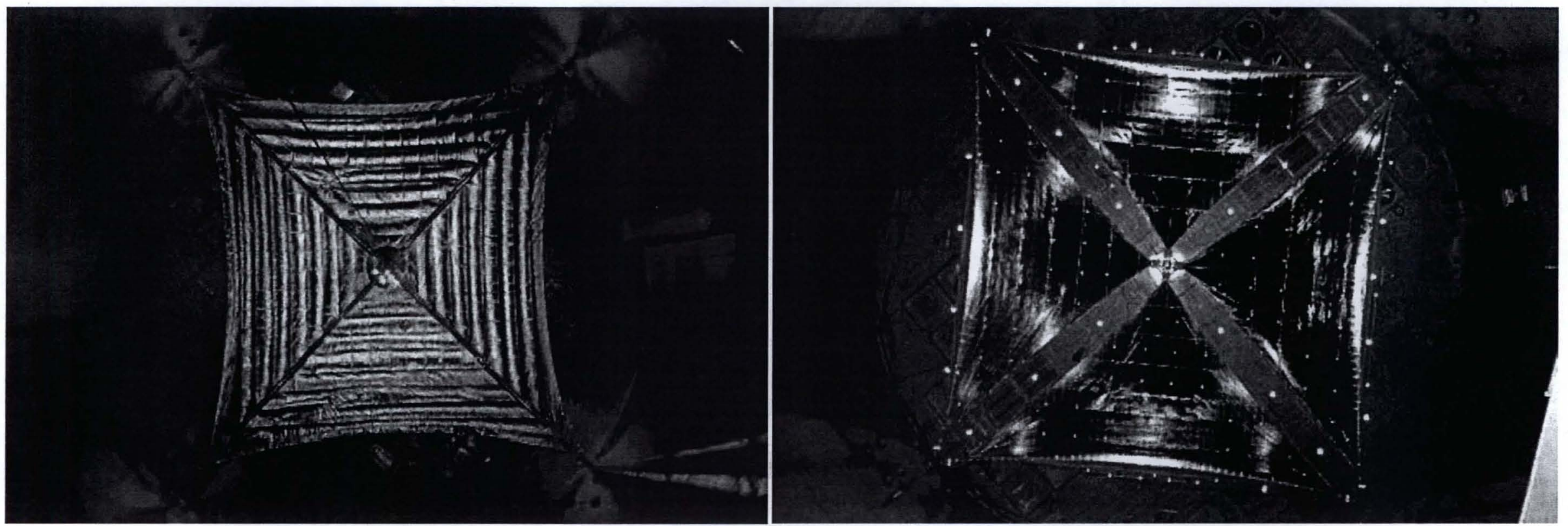

- Technology Area Status:

- Two parallel awards to design, fabricate, and test competing sail concepts for system level ground demonstration:

- $10 \mathrm{~m}$ system ground demonstrators were developed and tested in 2004.

- $20 \mathrm{~m}$ system ground demonstrators designed, fabricated, and tested under thermal vacuum conditions in 2005.

- Multiple awards to develop and test high-fidelity computational models, tools, and diagnostics.

- Multiple awards for materials evaluation, optical properties, long-term environmental effects, charging issues, smart adaptive structures. 


\section{0, 20, and 40-m Solar Sail Systems}

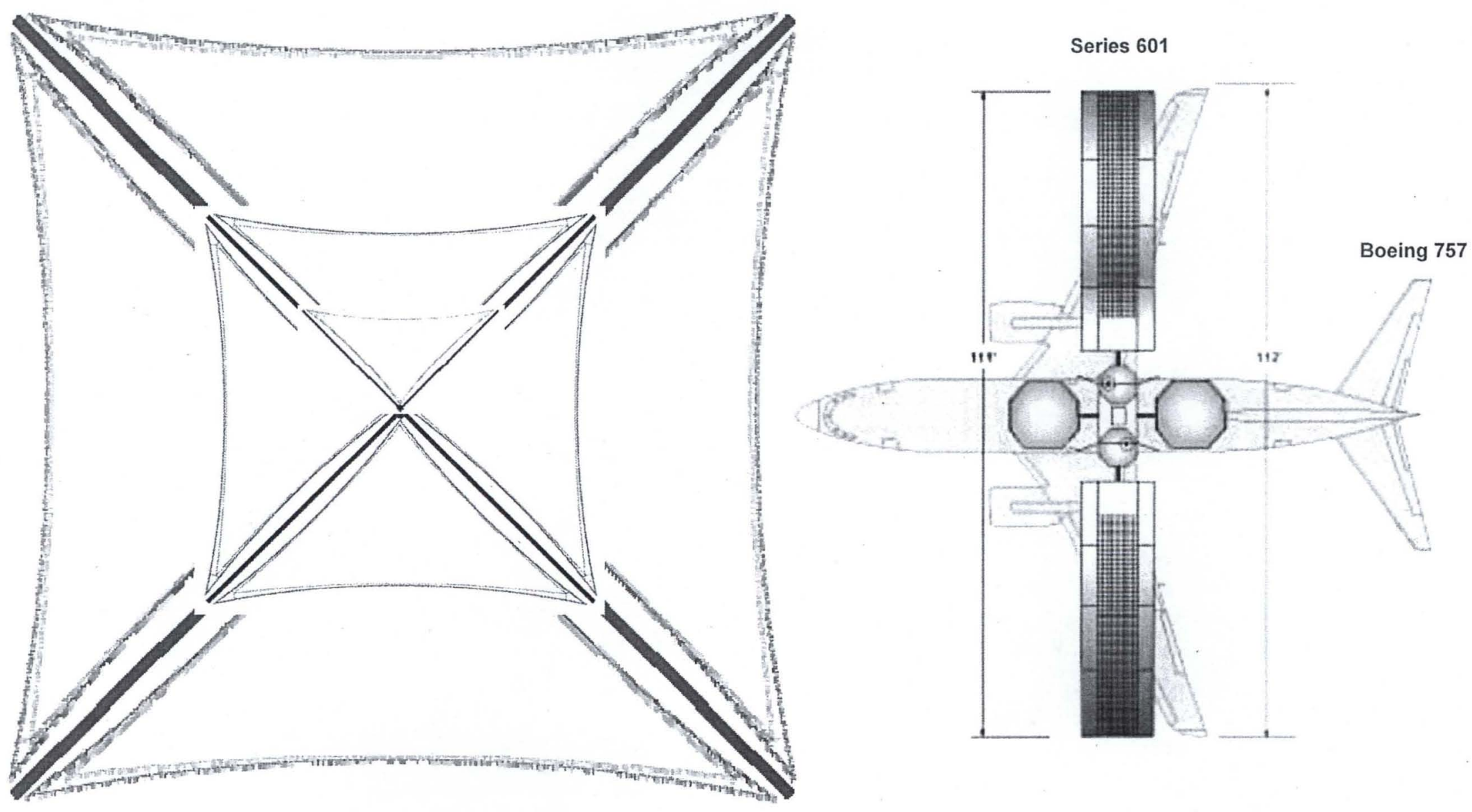




\section{ATK Solar Sail Development}

- PI: David Murphy, ATK Space Systems

- Proposal Team:

- ATK (Goleta, CA) systems engineering \& coilable booms

- SRS Technologies (Huntsville, AL): Sail manufacture \& assembly

- LaRC (Hampton, VA) Sail Modeling \& Testing

- MSFC (Huntsville, AL) Materials Testing

- Overall Strategy

- Leverages ST 7 Phase A Design

- Improve performance with Ultra-Light Graphite Coilable booms

- Synergy with SailMast Testbed selected to fly on ST8

- Sail membrane, AL coated 2-4 $\mu$ m CP1, compliant border, 3 point attach

- Thrust Vector Control uses sliding masses along boom with spreader bars and micro-PPT at mast tip
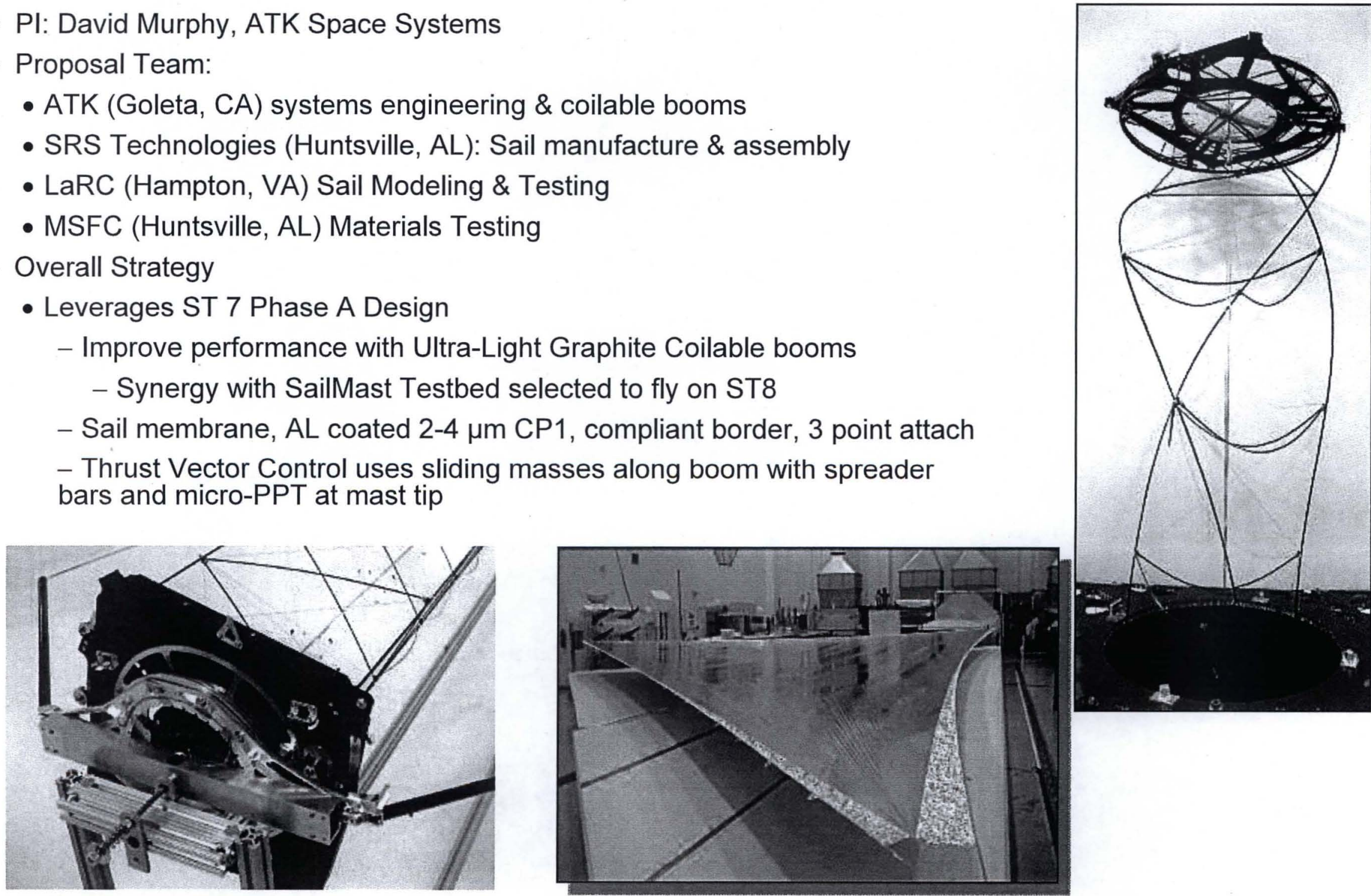


\section{CoilAble Mast Heritage}

- Able Engineering Company Established in 1975 (now ATK Space Systems)

- 30 CoilAble systems have been flown to date

- A phenomenal Stiffness to Weight ratio, High Dimensional Stability, Robust deployment, and Compact Stowage

- Recent flight mast designs

- Mars Pathfinder (1999) 1-meter boom: $130 \mathrm{~g} / \mathrm{m}$

- IMAGE spacecraft (2000) 10-meter booms: $93 \mathrm{~g} / \mathrm{m}$

- $100 \%$ Product Success Rate With No On-Orbit Failures

LACE

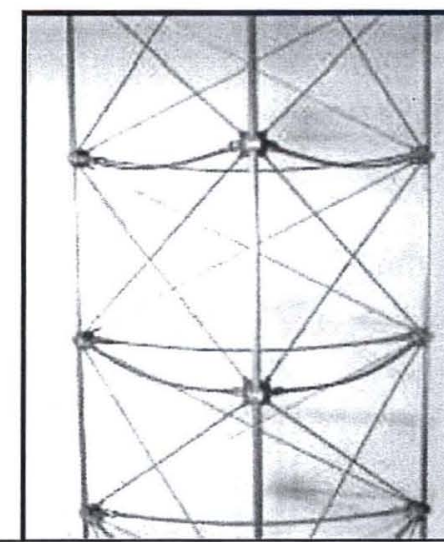

ISP

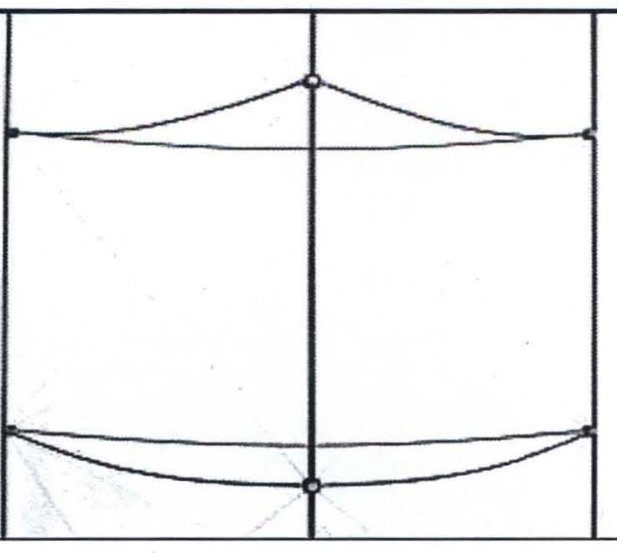

ST8

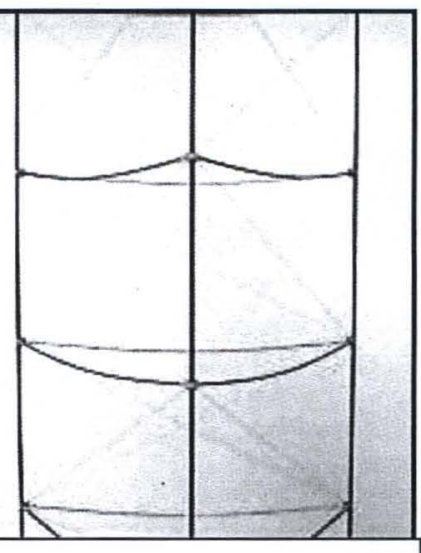

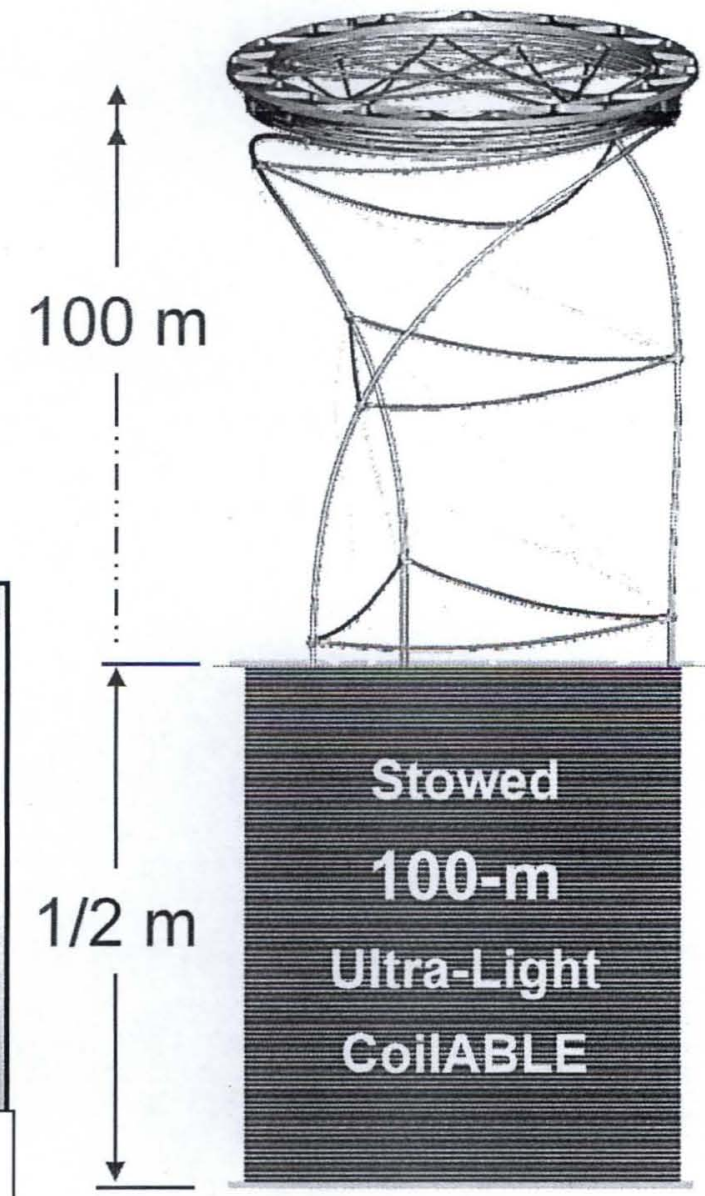




\section{SRS Solar Sail Membrane Features}

\section{Membrane Design:}

4-quadrant planar sail - 3-point sail attach with scalloped edges

- Designed determinant features, Biaxial membrane Design

- Compliant Border interface between edge cable and membrane

- Shear insensitive, Cord/Material CTE mismatch insensitive

- Thermal Gradient insensitive

\section{Sail Material: CP1 Polyimide}

- High Operating Temperature $\left(>200^{\circ} \mathrm{C}\right)$

- UV Stable

- Essentially Inert

- Soluble (Wet Process), modifiable with variety additives improve conductivity and thermal properties

\section{- 2 micron polyimide}

- Flight Proven --- flying on Numerous GEOCOM satellites

\section{Sail Construction Methods:}

A gossamer film construction similar to gusseted, reflective blankets flying on numerous GEOCOM satellites

- Scalable Construction Methods --- current system $>20 \mathrm{~m}$

- Adhesive less Bonding Methods --- eliminates sticking and contamination risks.

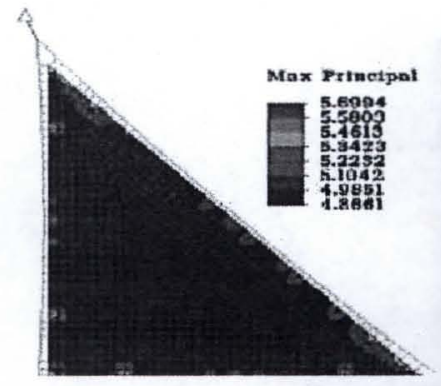

FEM of Parobolic Edge

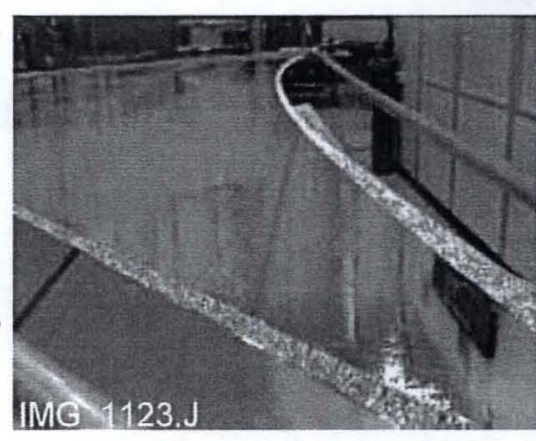

\section{Sail with Compliant} Border

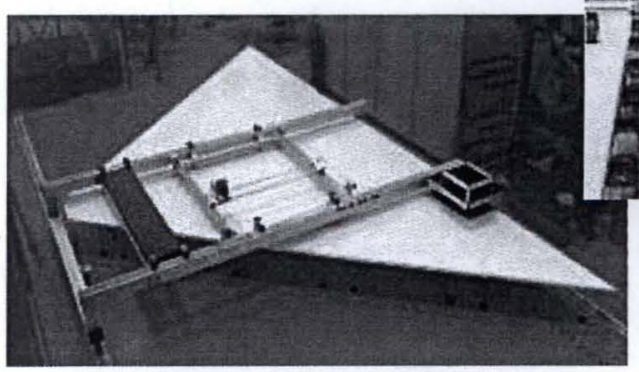

SRS CNC Seaming System
$160 \mathrm{~m}^{2}$ of film per satellite. Film Is 1 mil material supported by 5 mil edge designs

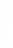




\section{ATK Ambient Deployment at Plum Brook}

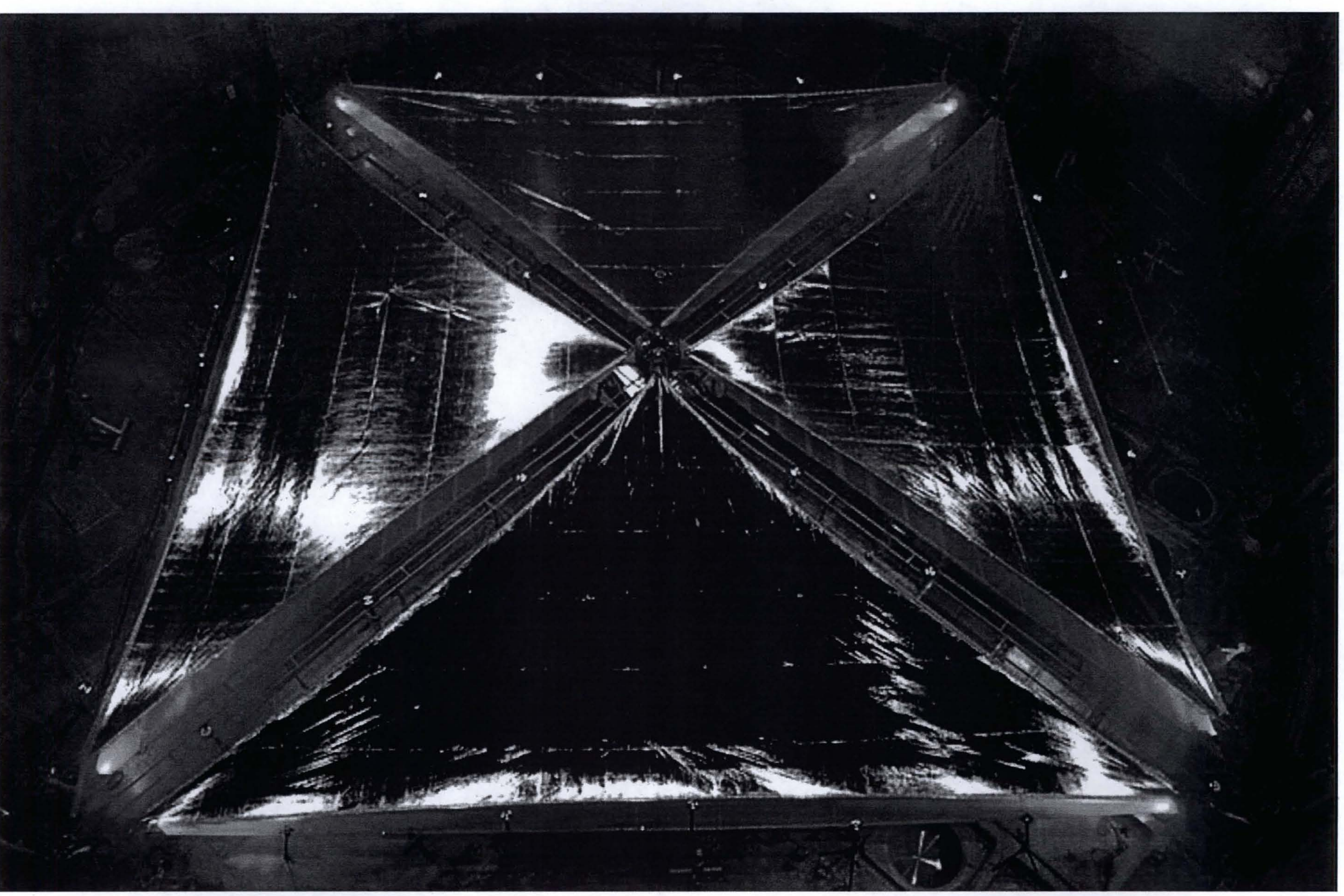




\section{L'Garde Solar Sail Development}

- PI: David (Leo) Lichodziejewski, L'Garde, Inc.

- Proposal Team:

- L'Garde, Inc. (Tustin, CA) systems engineering and inflatable truss

- Ball Aerospace \& Tech Corp. (Boulder, CO) mission eng. \& bus design

- LaRC (Hampton, VA) sail modeling \& testing

- JPL (Pasadena, CA) mission planning \& space hazards

- Overall Strategy

- Concept Leverages ST-5 Phase A and Team Encounter experience

- Sail membrane, AL coated $2 \mu \mathrm{m}$ Mylar attached with stripped net

- Lightweight Semi-monocoque Boom With Sub-Tg Rigidization

- 4 Vane Thrust Vector Control
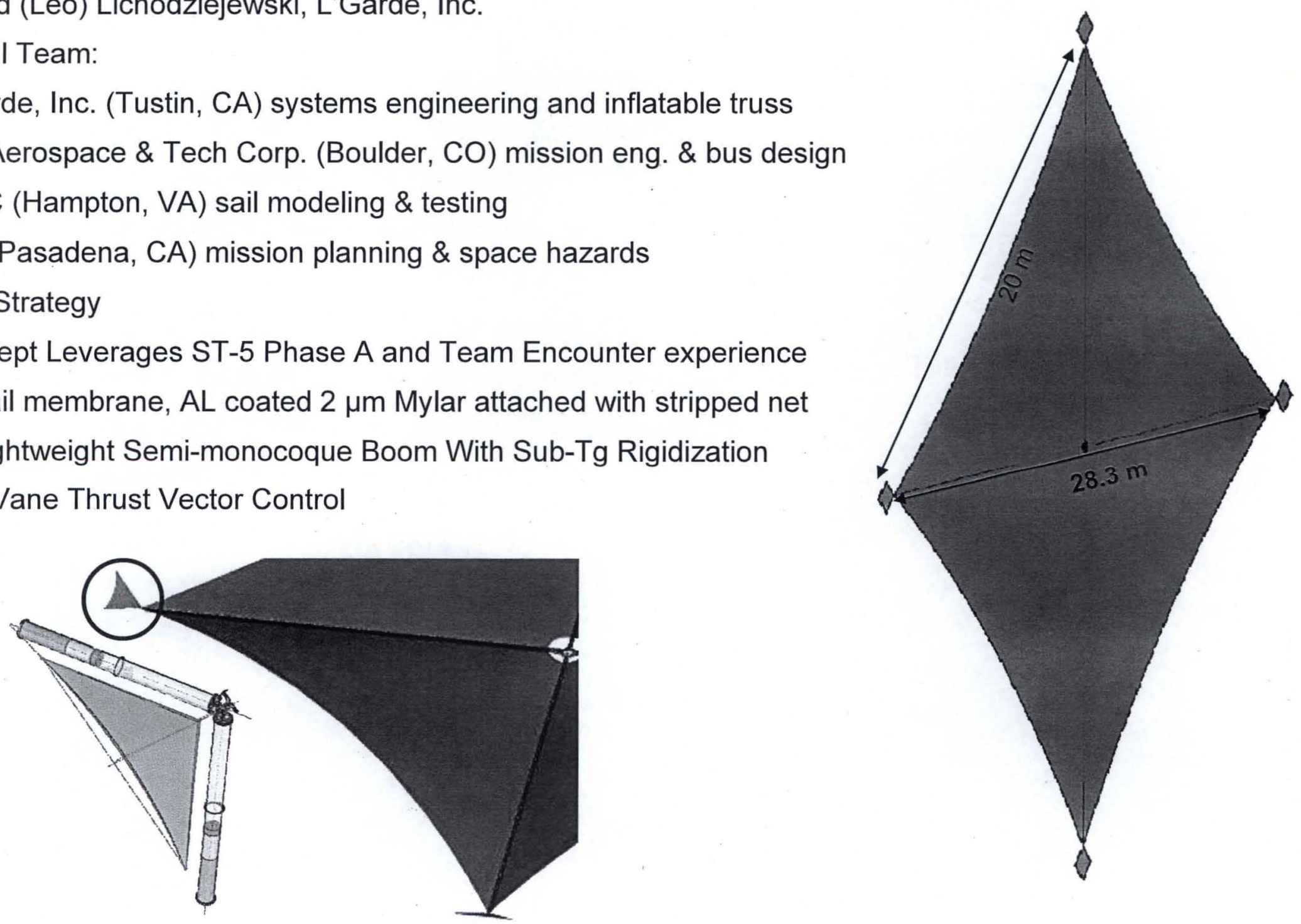


\section{Beam Design}
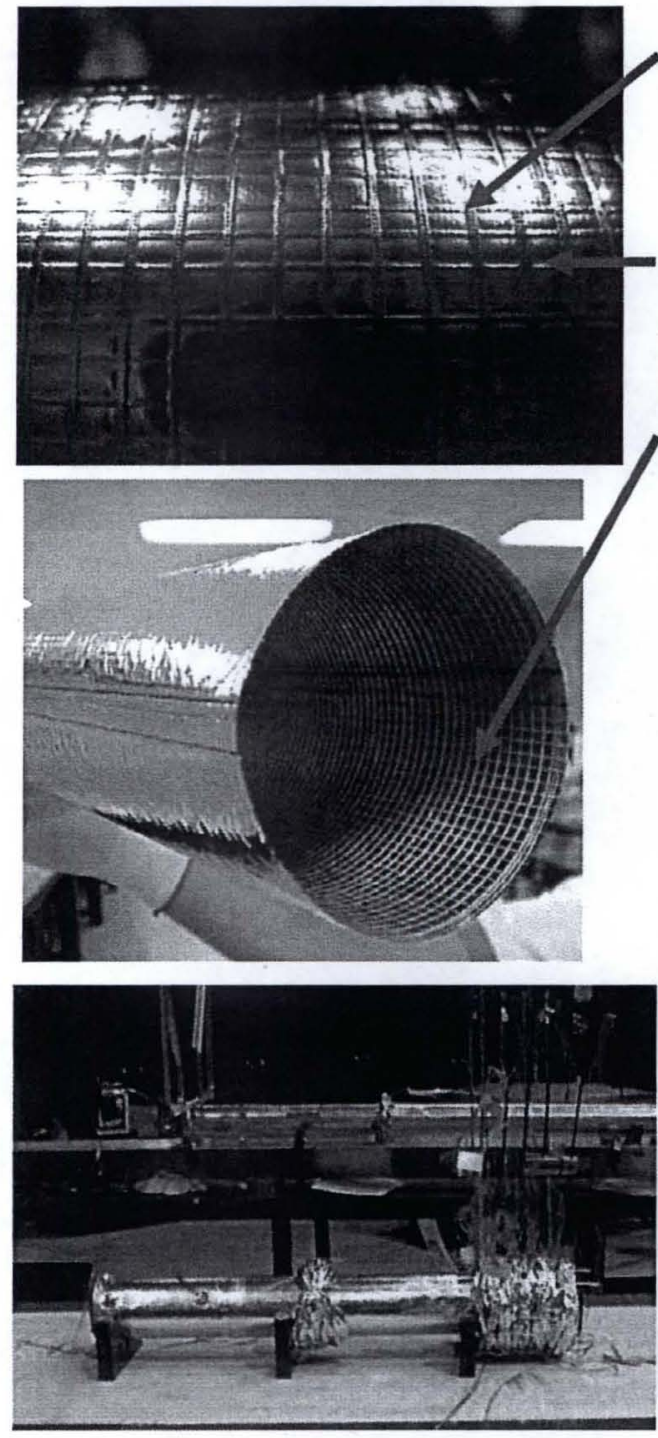

Stowed $7 \mathrm{~m}$ boom $(\sim .5 \mathrm{~m})$

\section{Load bearing longitudinal uni-directional fibers}

- Fibers impregnated with resin (rigid below $-20^{\circ} \mathrm{C}$ )

- 0.48 AU design requires greater fiber density to withstand loads from the increased solar flux

Spiral wrap

- Stabilizes longitudinal fibers

- Allows over-pressurization for deployment anomalies Bonded Kapton bladder and Mylar

- Encapsulation "skin" carries shear

- Aircraft fuselage like structure

\section{Beam Structure}

- Sail structure is stressed for solar loading in one direction for mass efficiency

- Truss system comprised of mostly tension elements, minimal rigid components

- Highly mass efficient, $\sim 36 \mathrm{~g} / \mathrm{m}$ linear density

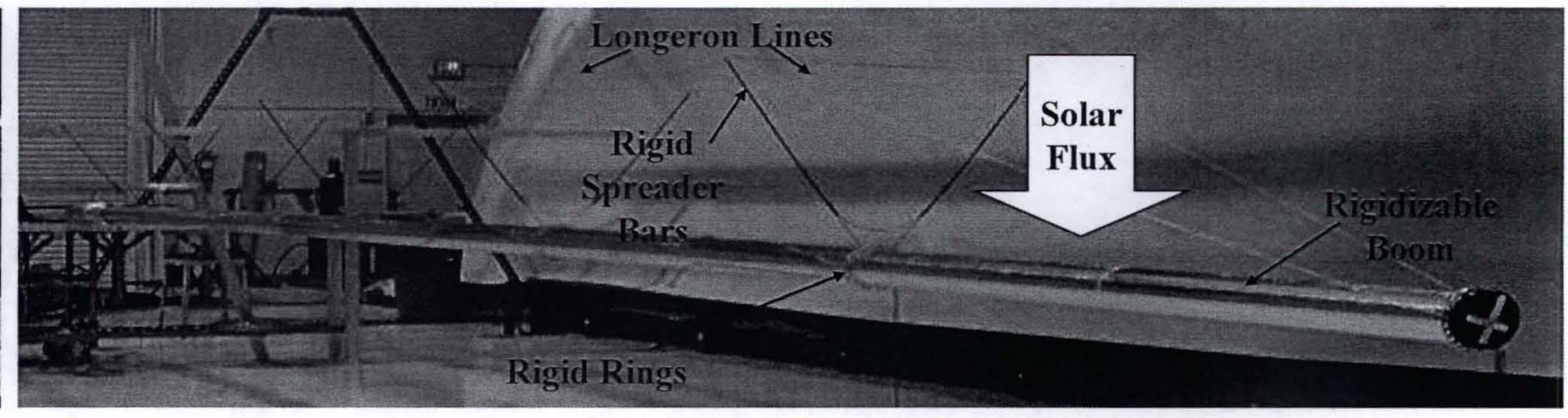

Deployed $7 \mathrm{~m}$ boom 


\section{Net/Membrane Sail Design}

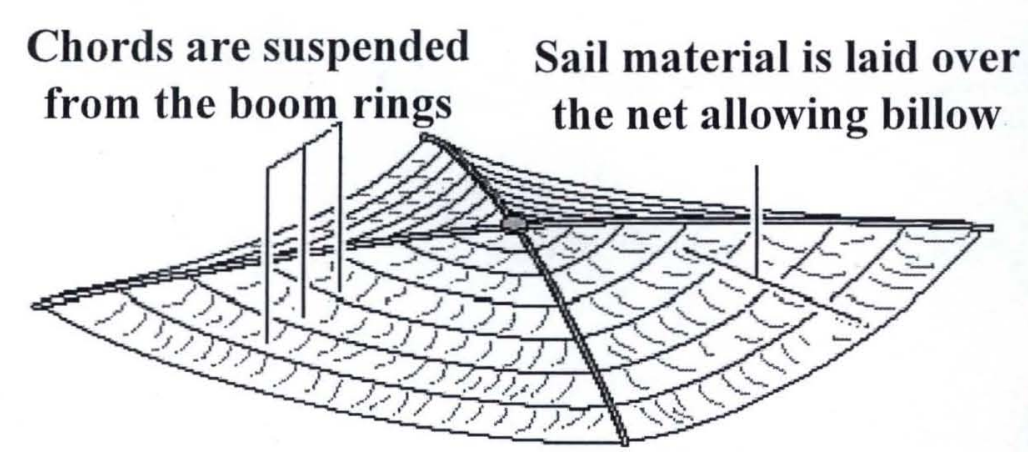

Net/Membrane Sail Schematic

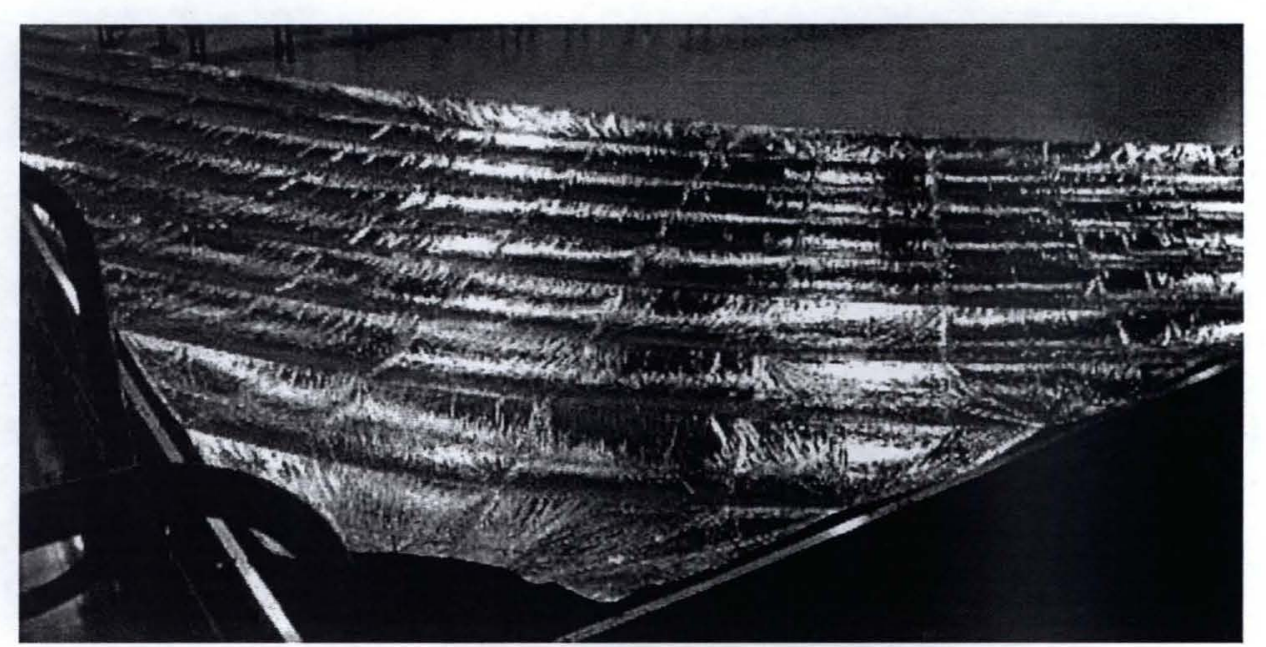

20m Sail Quadrant

Net Membrane

- Sail is supported by a low CTE net with additional membrane material added to allow for thermal compliance

- Sail properties effect local billow between net members only, global sail shape is stable

\section{Advantages}

- Net defines the overall sail shape, not the membrane

- Stability and geometry of the sail is effectively decoupled from membrane properties

- Sail shape, and hence thrust vector, sailcraft stability and performance, are predictable and stable

- No high local stress concentrations in the sail, loads are transferred though the net, not the membrane

- Very scalable, larger net/membrane sails simply add additional net elements to control overall shape

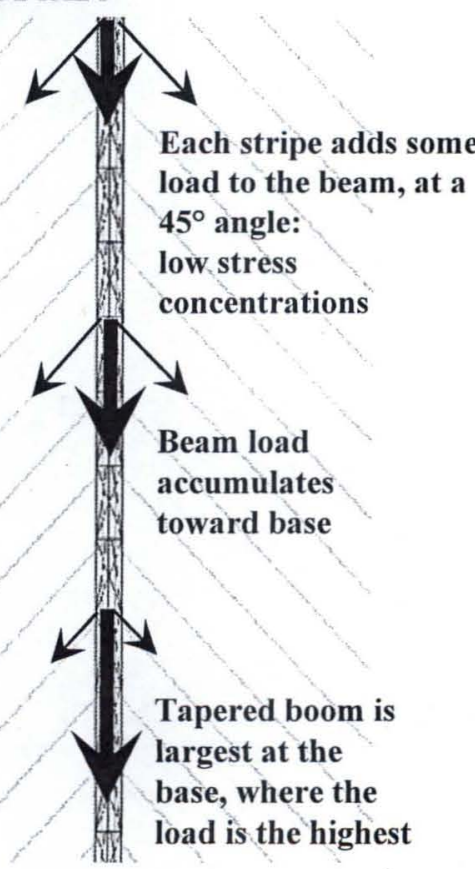




\section{L'Garde Ambient Deployment at Plum Brooknasa}

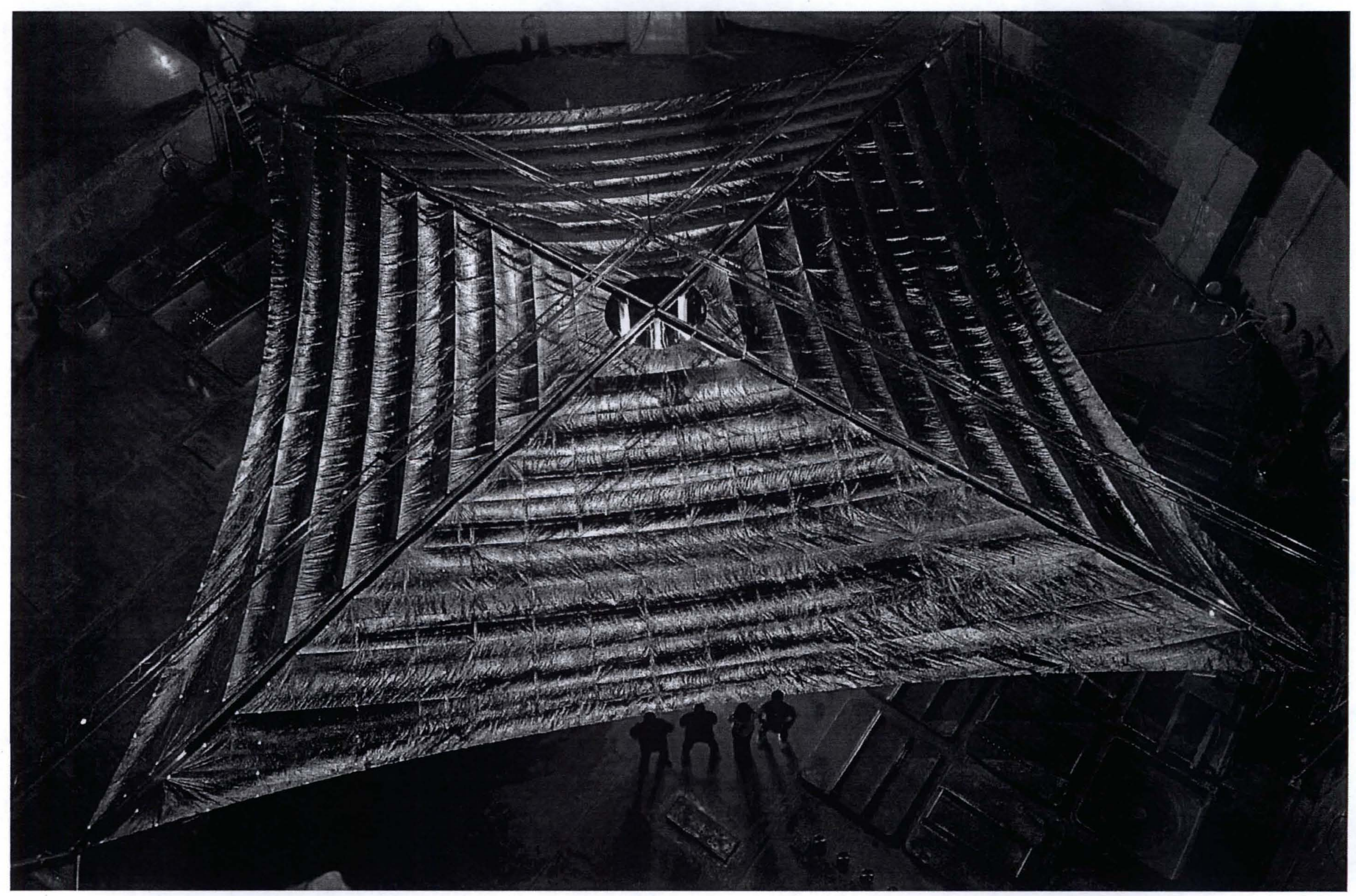




\section{Solar Sail Subsystem Development}
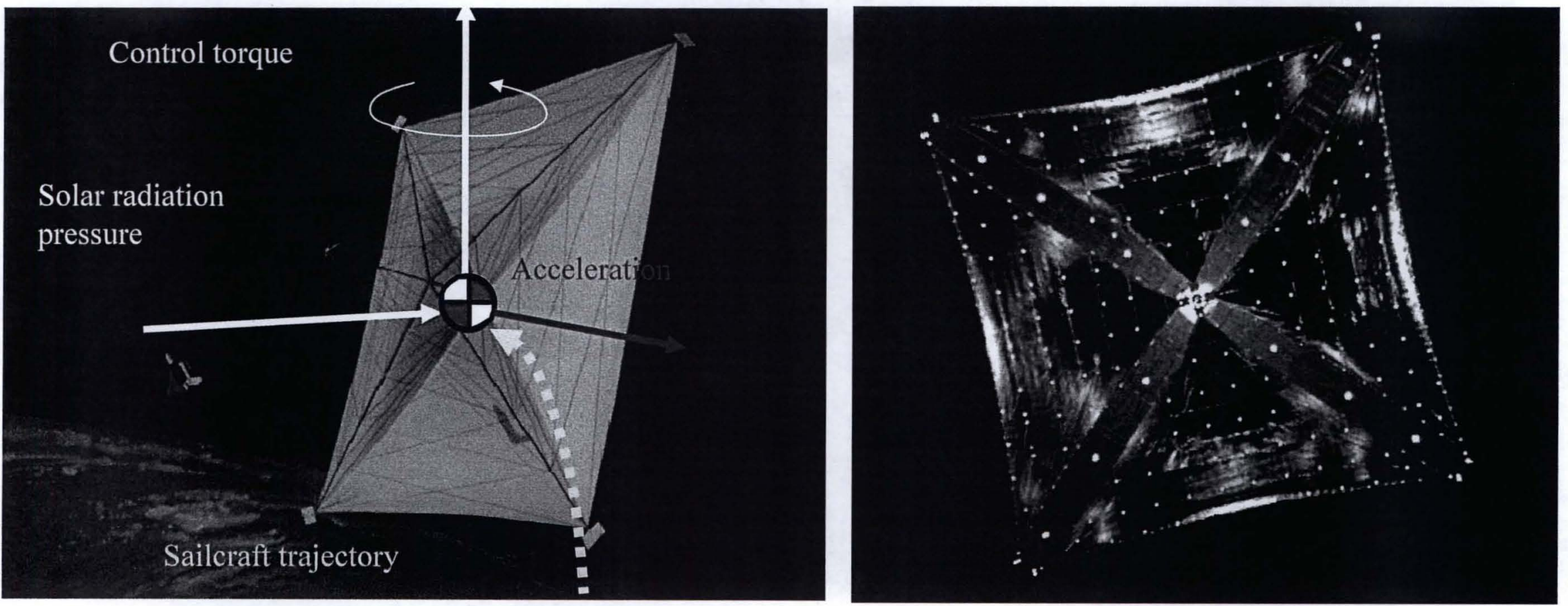

Solar Sail Spaceflight Simulation Software (S5)

Develop an integrated simulation and analysis software tool for optimal design of solar sail trajectories and for evaluation of guidance navigation and control strategies.

Optical Diagnostic System (ODS) Develop a lightweight integrated instrumentation package to allow measurement of sail shape, tension and temperature; boom \& sail vibration modes and stress; and deployment monitoring. 


\section{Solar Sail Subsystem Development- cont.}

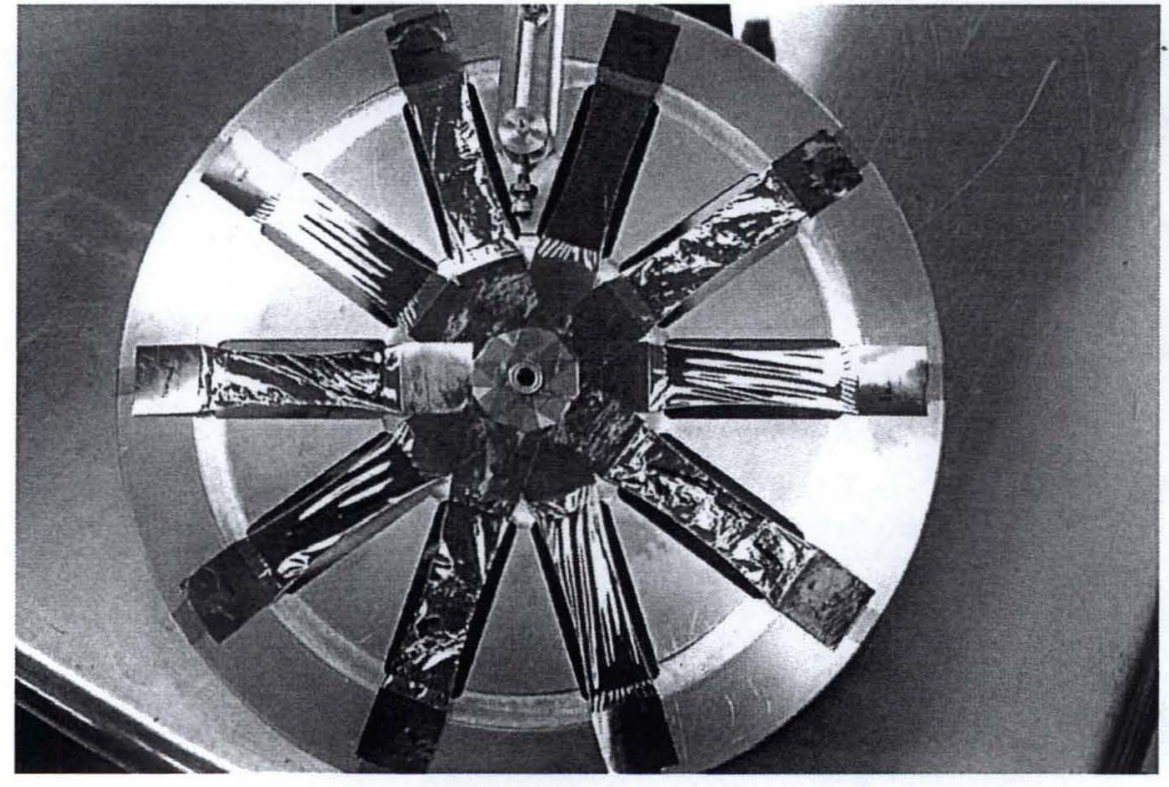

Samples prior to UV exposure

\section{Material Testing}

Characterize engineering performance of candidate SS materials at .5 and $1 \mathrm{AU}$, gauging material property tolerances after exposure to emulated missionspecific charged-particle and micrometeoroid environments.
Able's Solar Sail Mast with a Trim Control Mass (TCM), Roll Spreader Bars (RSBs), and microPPTs

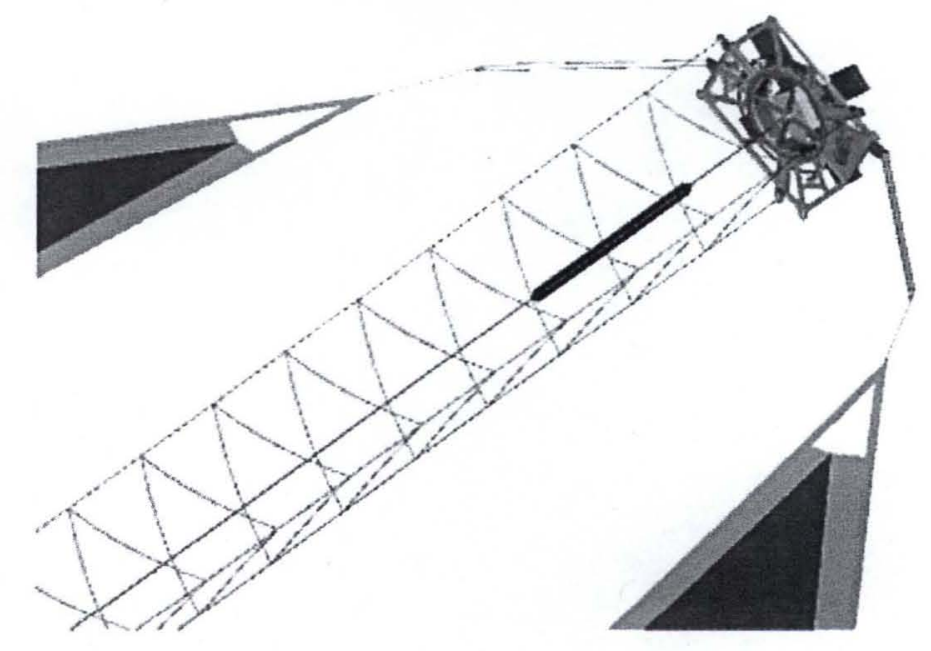

Development of a Lightweight Robust SACS and a Software Toolkit for Solar Sails

Develop of a highly integrated, low cost, low mass, low volume, and low power attitude determination and control system and develop a high-fidelity multi-body modeling and simulation software toolkit. 


\section{Solar Sail Subsystem Development- cont.}

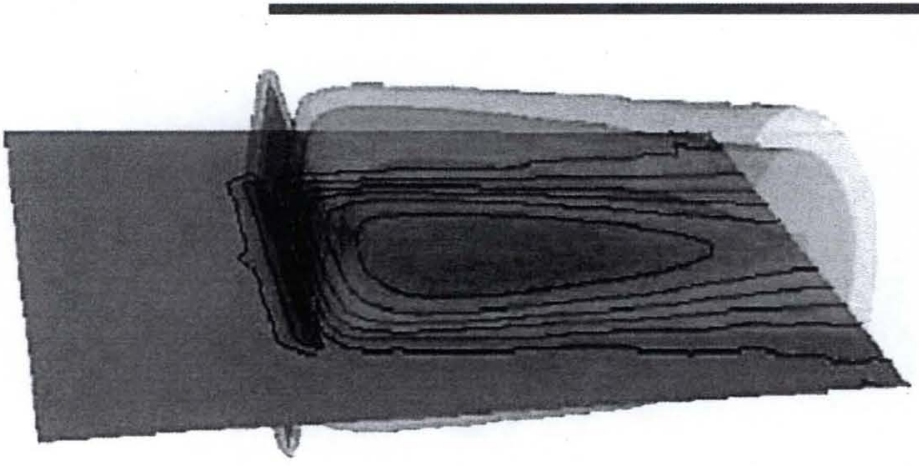

VT Plasma Flow Model of sail in the solar wind with the potentials normalized by $0.25 \mathrm{Te}$

Sail Charging Analysis

Develop environmental and sail configuration models and design guideline criteria for solar sails. Conduct laboratory assessment of potential for destructive charging fields and arcing events within the sail and surrounding environment.
Smart Adaptive Structures Identify nonlinear mechanism for existing $\mathbf{4 0}$ meter coilable boom. Assess potential for control structures interactions.

Advanced Manufacturing Technologies Develop and refine the technology of sail assembly for manufacturing large monolithic sails, improving membrane coating processes and technologies
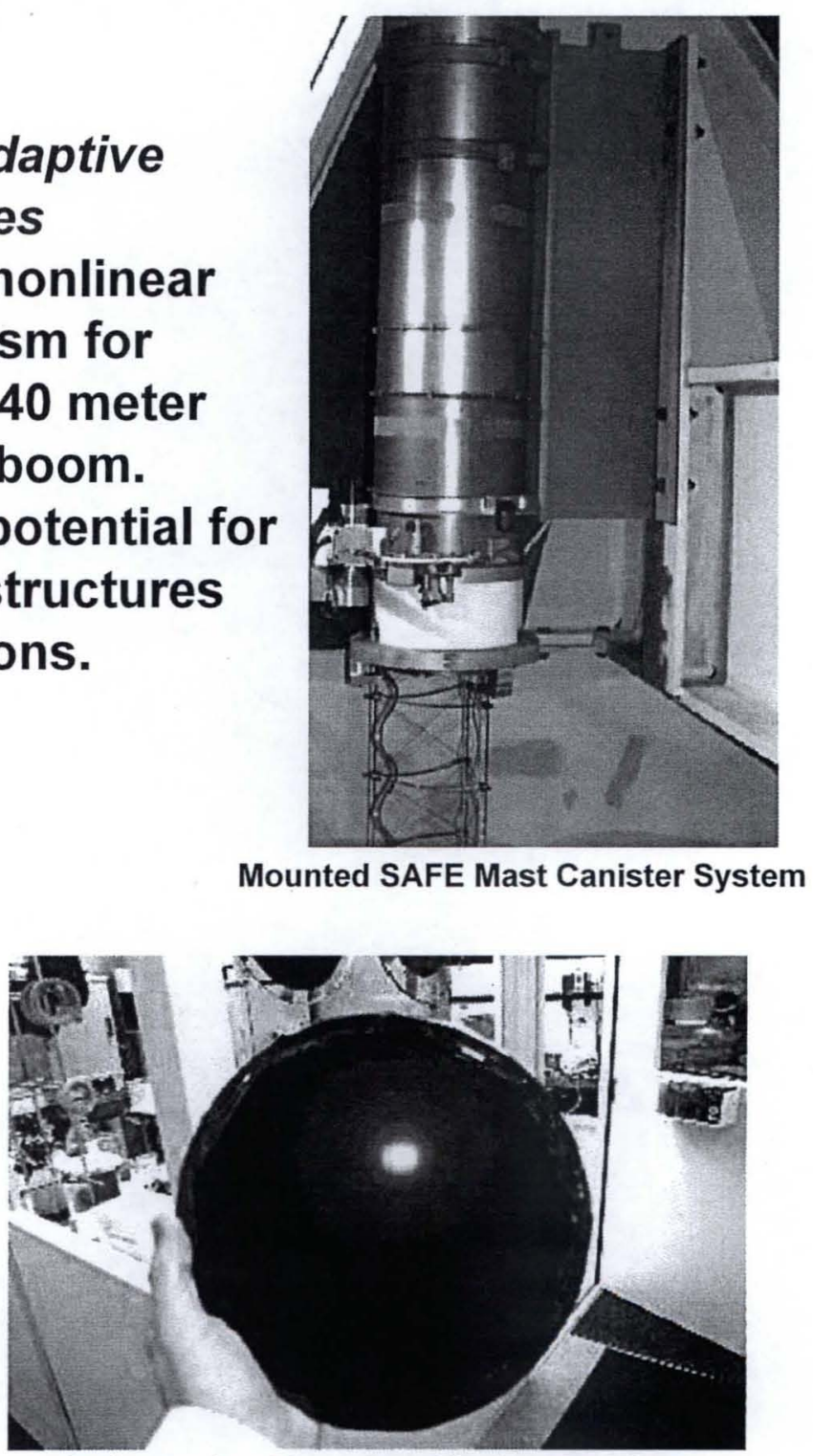

Sail sample with carbon black nanotubes 


\section{Solar Sail Propulsion Notables}

- Designed, built, delivered, and safely tested in a ground environment two $20 \mathrm{~m}$ solar sail systems using different technologies

- Subjected materials to high doses of radiation verifying on-orbit life time characteristics

- Developed a flight mechanics simulation capable of modeling non-Keplerian orbits

- Conducted static and dynamic response tests and multiple deployments of two 400 square meter sails from a one cubic meter box at a high vacuum in the largest horizontal space test chamber in the world (Plum Brook). $500 \mathrm{~Gb}$ of data generated.

- Subjected stowed systems to launch loads and ascent vent tests prior to deployment.

- Measured Modal Test Frequencies matched predicted values to within ten percent.

- Developed repair techniques for membranes and booms.

- Developed and used in test the largest high resolution photogrammetric shape measurement system in the world.

- Developed a mission concept to extend warning times to Earth for damaging solar events from 30 minutes to 90 minutes.

- Successfully applied conventional finite element modeling techniques to large area gossamer space structures.

- Determined the extent to which gossamer structures can be verified by test on the ground.

- Identified a tendency for torsional dynamic modes in the booms to migrate to bending modes.

- Discovered that wrinkles and other small defects have minimal impact on propulsion performance.

- Discovered significant robustness against spacecraft charging. 


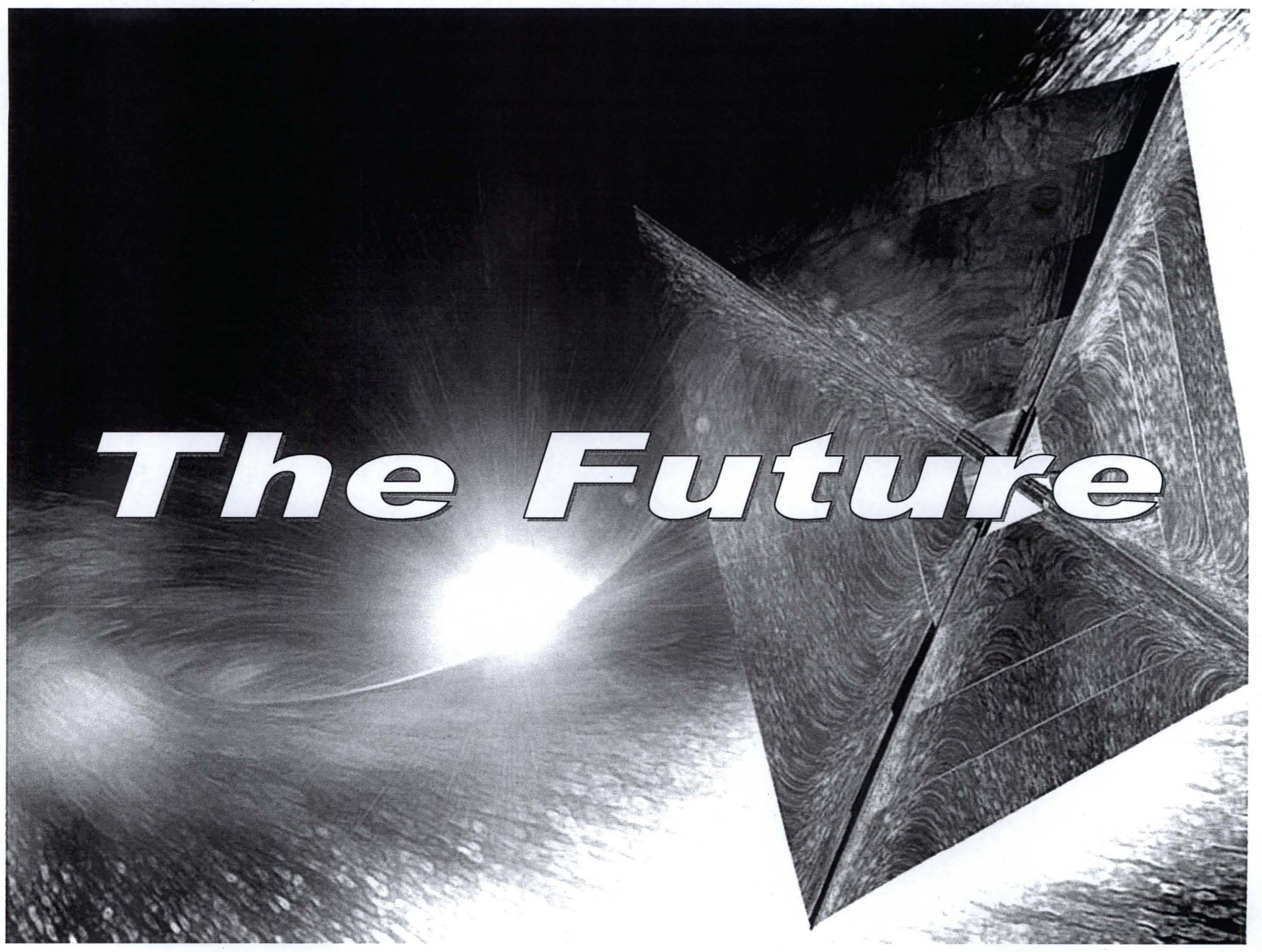




\section{Solar Sails: The Race to the Heliopause}

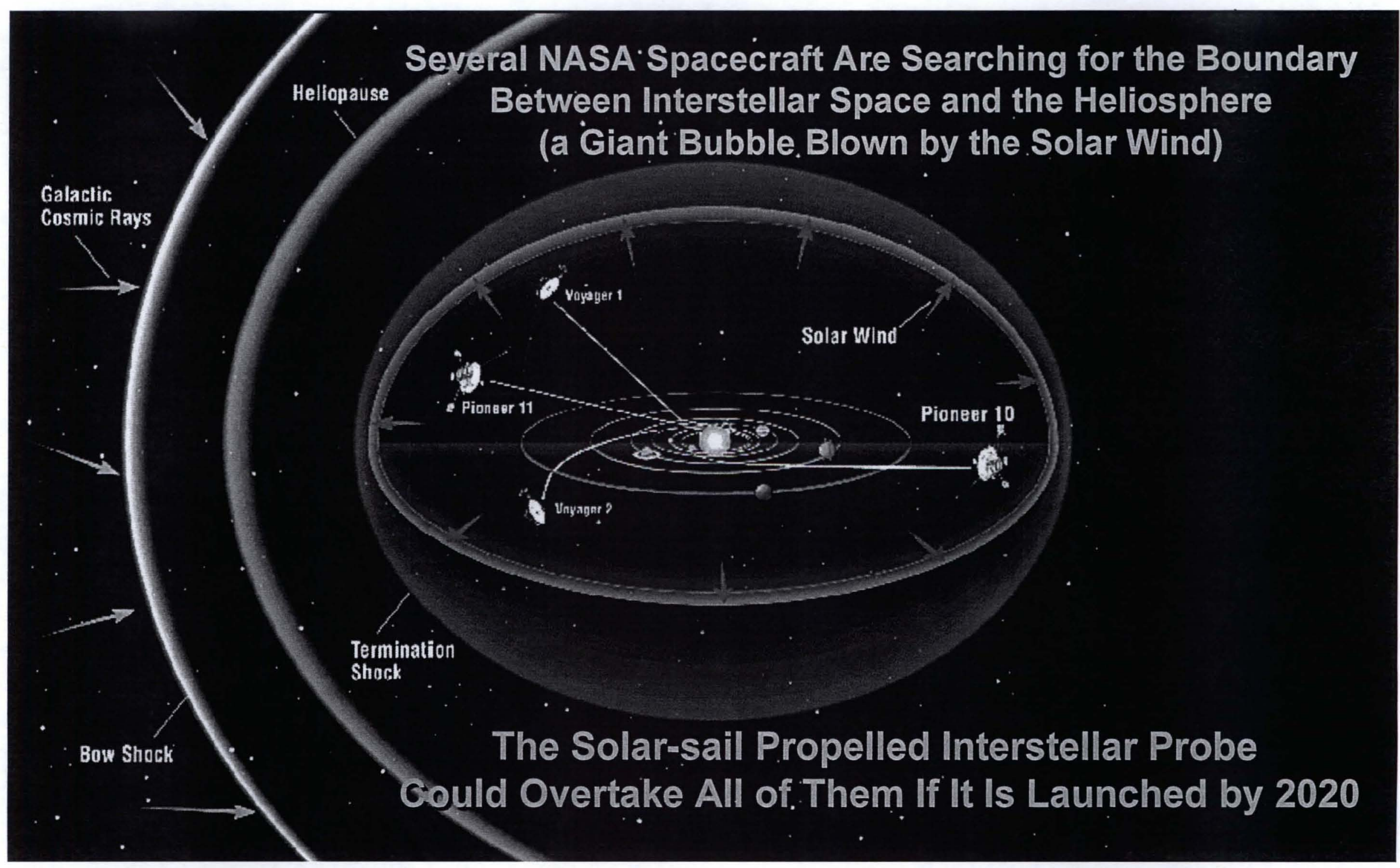




\section{Solar Sails: \\ Ultimate Goal- $200 \mathrm{AU}$ with $<15$ year trip time}

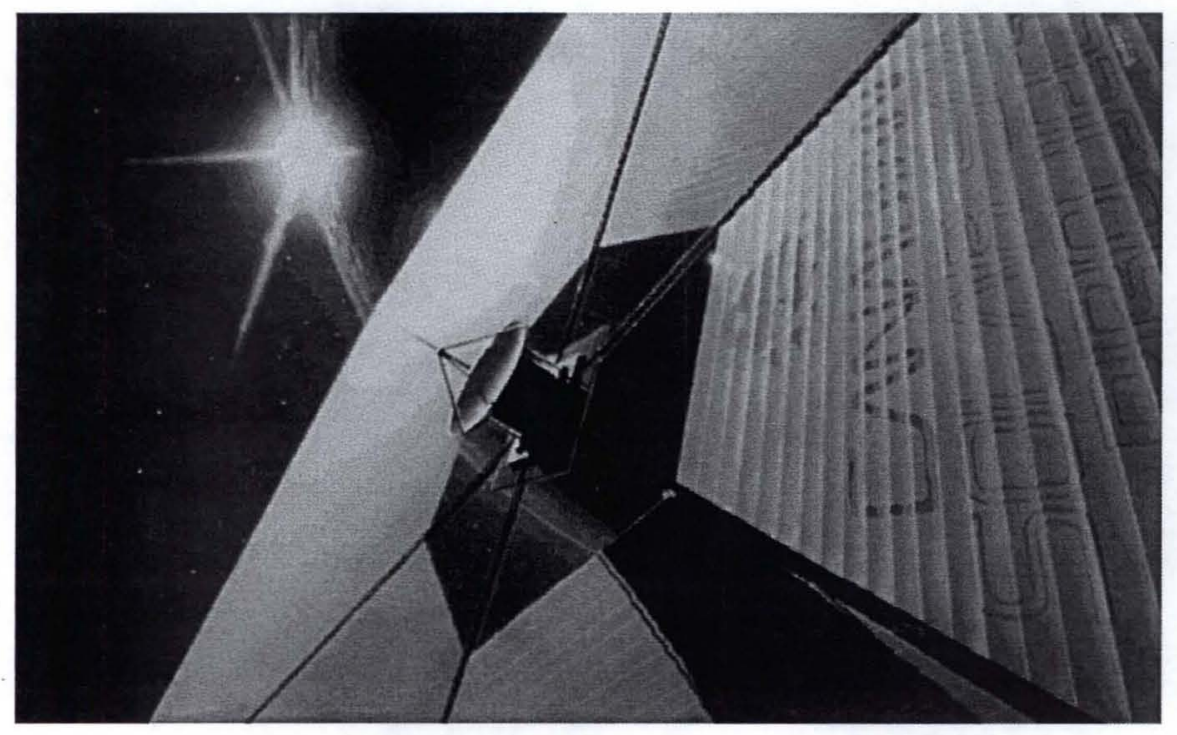

- Systems Requirements

- Travel Distance - 200 AU

- Travel Time $<15$ years

- $\Delta \mathrm{V}>60 \mathrm{~km} / \mathrm{s}$

- Material Challenges

- High Temperature Tolerance 70 -2000K

(@ 200 - $0.25 \mathrm{AU}$ )

- High Emissivity 0.4-0.9

- High Tensile Strength

- Good Gamma and UV Radiation Tolerance

- Low Coefficient of Thermal Expansion

$3 \times 10-6$ (per $\left.{ }^{0} \mathrm{C}\right)$

- Sail Fabric Areal Density $0.5 \mathrm{~g} / \mathrm{m}^{2}$

- Fabric Thickness $<0.35 \mu \mathrm{m}$

(polyimide $\rho=1.4 \mathrm{gm} / \mathrm{m}^{3}$ )

- Sail Structure Areal Density $0.5 \mathrm{~g} / \mathrm{m}^{2}$ 


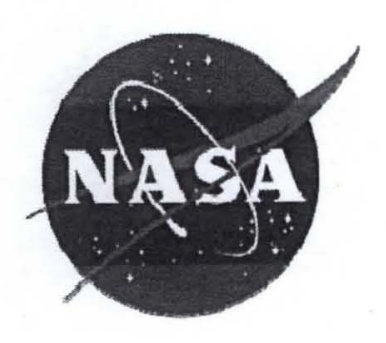

www.nasa.gov 


\section{AEC Concept Refinement Study Results}

- Operating Temperature $>16^{\circ} \mathrm{C}$ at .98 au

- First Natural Frequency $>0.02 \mathrm{~Hz}$

- Stowed Package > $1.5 \mathrm{~m}$ dia. by $0.53 \mathrm{~m}$

- Control Boom $>$ 3.75-m length

- System Mass:

$>108 \mathrm{~kg}$ (w/ contingency)

$\rightarrow$ Characteristic acceleration $>0.76 \mathrm{~mm} / \mathrm{s}^{2}$

$>0.34 \mathrm{~mm} / \mathrm{s}^{2}$ with $130 \mathrm{~kg} \mathrm{SC}$

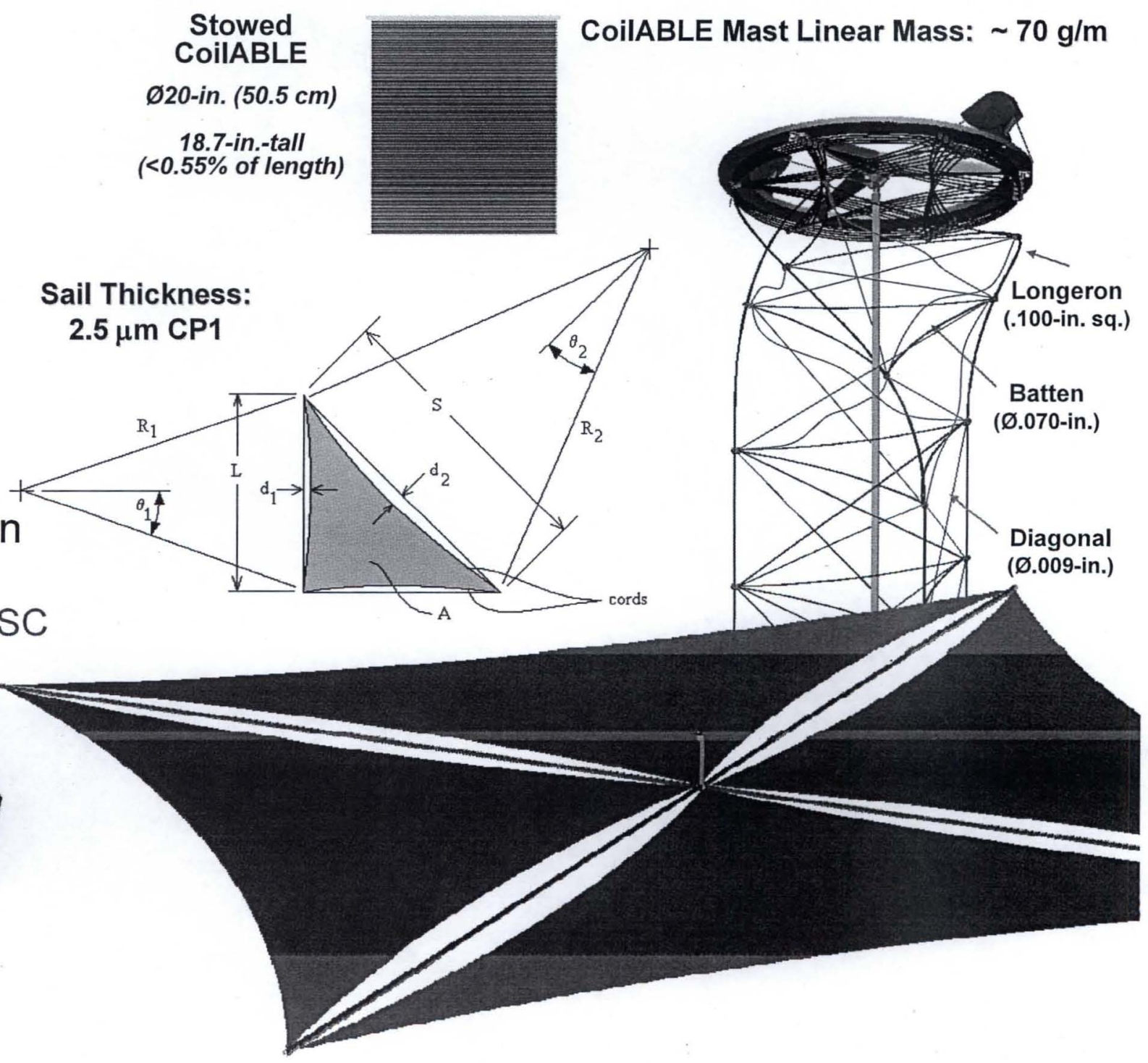




\section{$1^{\text {st }}$ Full System Deployment: 2-17-04}

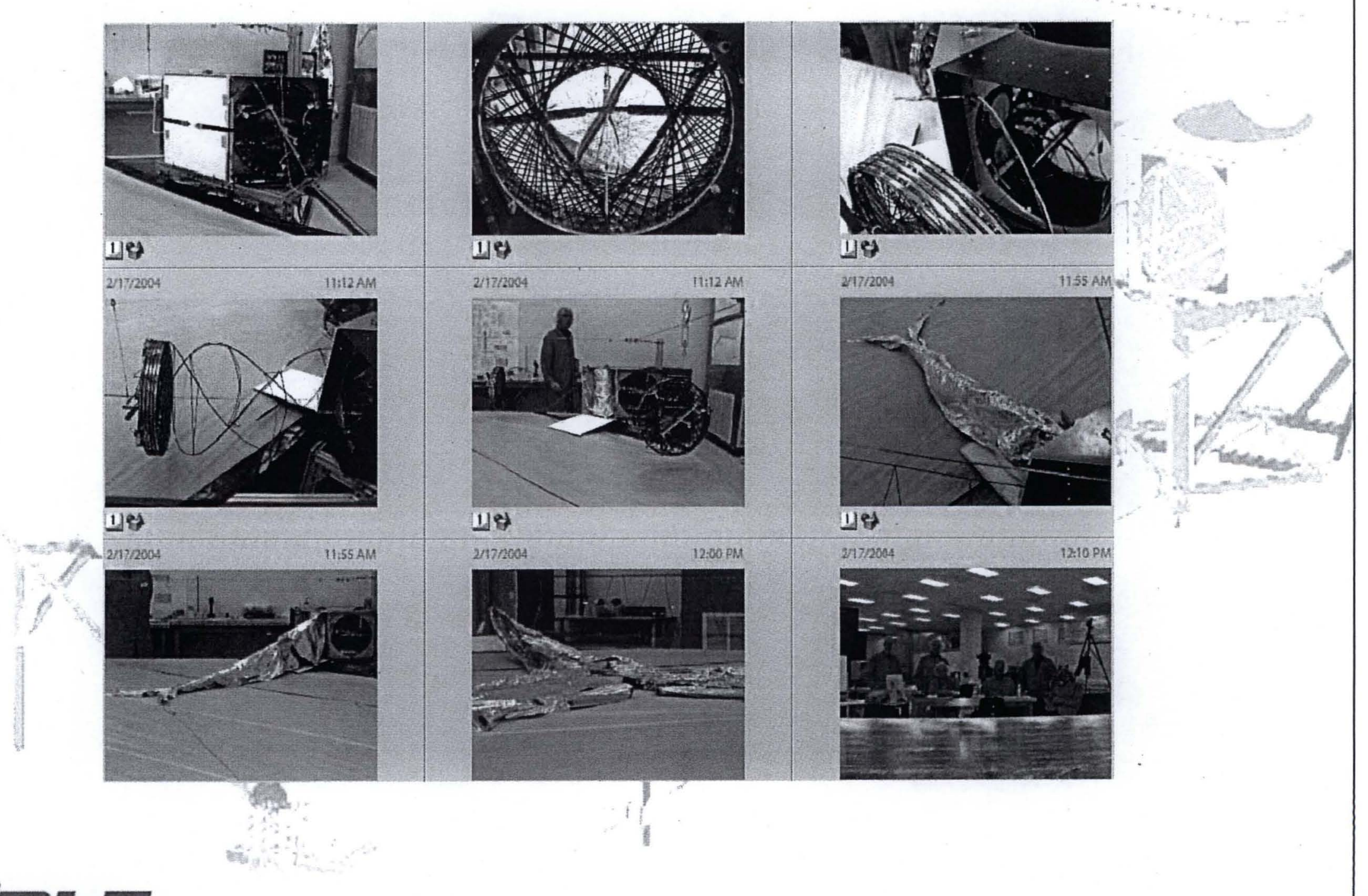




\section{L'Garde Solar Sail Demonstrator Task Summary}

- PI: David (Leo) Lichodziejewski, L'GARDE, Inc.

- Proposal Team:

- L'GARDE, Inc. (Tustin, CA) systems eng. and inflatable truss

- Ball Aerospace \& Tech Corp. (Boulder, CO) mission eng. \& bus design

- LaRC (Hampton, VA) sail modeling \& testing

- JPL (Pasadena, CA) mission planning \& space hazards

- Overall Strategy

- Concept Leverages ST-5 Phase A and Team Encounter experience

- Sail membrane, AL coated $2.5 \mu \mathrm{m}$ Mylar

- 4 Vane ACS

- Hardware Testing Phases

- ø2:Test Four 10-m quadrant (6/03-5/04),

- Four 8-m Inflatable/Rigidizable booms, 10-m Mylar membrane, boom support equipment

- Testing at L'GARDE (ambient) and LaRC (16-m vacuum)

-Ascent venting, Launch vib., Deployment, Mast modes, Sail Modes, System Modes

- ø3: Test four quadrant 20-m Sail System (6/04-6/05)

- Four 14-m Inflatable/Rigidizable booms, center structure, Vane and actuator

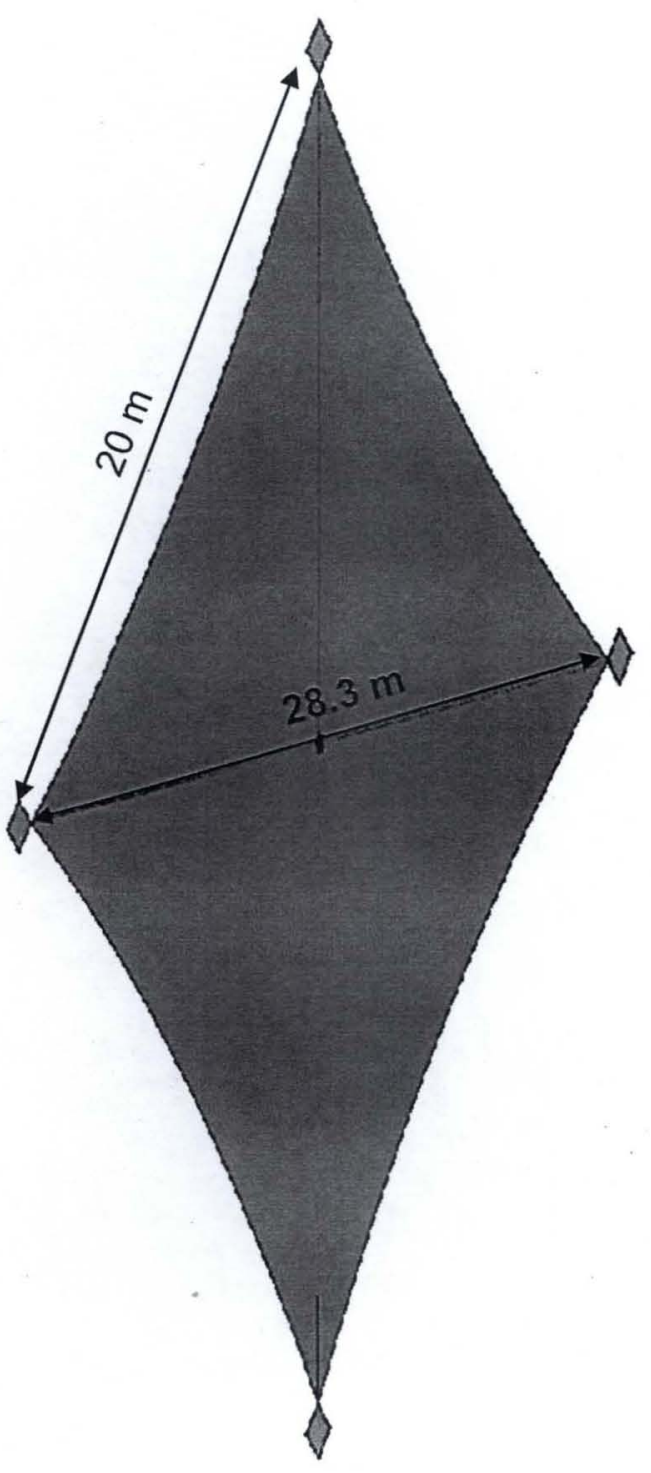

- Testing at L'GI (ambient) and GRC-PF (30-m vacuum) 